\title{
Silicon Carbide Micro-devices for \\ Combustion Gas Sensing under Harsh Conditions
}

Reporting Period:

September 1, 2005 to March 31, 2006

Ruby N. Ghosh ${ }^{1}$, Reza Loloee ${ }^{1}$, Roger G. Tobin ${ }^{2}$ and Yung Ho Kahng ${ }^{2}$

April 2006

DOE Award Number: DE-FC26-03NT41847

\author{
${ }^{1}$ Dept. of Physics \& Astronomy \\ 2167 Biomedical Physical Sciences Building \\ Michigan State University \\ ${ }^{2}$ Dept. of Physics and Astronomy \\ 4 Colby St. \\ Tufts University
}




\section{DISCLAIMER}

"This report was prepared as an account of work sponsored by an agency of the United States Government. Neither the United States Government nor any agency thereof, nor any of their employees, makes warranty, express or implied, or assumes any legal liability or responsibility for the accuracy, completeness, or usefulness of any information, apparatus, product, or process disclosed, or represents that its use would not infringe privately owned rights. Reference herein to any specific commercial product, process, or service by trade name, trademark, manufacturer, or otherwise does not necessarily constitute or imply its endorsement, recommendation, or favoring by the United States Government or any agency thereof. The views and opinions of the authors expressed herein do not necessarily state or reflect those of the United States Government or any agency thereof."

\section{$\underline{\text { ABSTRACT }}$}

A sensor based on the wide bandgap semiconductor, silicon carbide ( $\mathrm{SiC})$, has been developed for the detection of combustion products in power plant environments. The sensor is a catalytic gate field effect device that can detect hydrogen-containing species in chemically reactive, high temperature environments. For fast and stable sensor response measurements, a gate activation process is required. Activation of all sensors took place by switching back and forth between oxidizing (1.0\% oxygen in nitrogen) and reducing (10\% hydrogen in nitrogen) gases for several hours at a sensor temperature $\geq 620^{\circ} \mathrm{C}$. All 52 devices on the sensor chip were activated simultaneously by flooding the entire chip with gas. The effects of activation on surface morphology and structure of Pt gates before and after activation were investigated. The optical images obtained from Pt gates demonstrated a clear transition from a smooth and shiny surface to a grainy and cloudy surface morphology. XRD scans collected from Pt gates suggest the presence of an amorphous layer and species other than $\mathrm{Pt}$ (111) after activation.

The reliability of the gate insulator of our metal-oxide-SiC sensors for long-term device operation at $630{ }^{\circ} \mathrm{C}$ was studied. We find that the dielectric is stable against breakdown due to electron injection from the substrate with gate leakage current densities as low at $5 \mathrm{nA} / \mathrm{cm}^{2}$ at $630{ }^{\circ} \mathrm{C}$. We also designed and constructed a new nano-reactor capable of high gas flow rates at elevated pressure. Our reactor, which is a miniature version of an industrial reactor, is designed to heat the flowing gas up to $700{ }^{\circ} \mathrm{C}$.

Measurements in ultrahigh vacuum demonstrated that hydrogen sulfide readily deposits sulfur on the gate surface, even at the very high hydrogen/hydrogen sulfide ratios $\left(10^{3}-10^{5}\right)$ expected in applications. Once deposited, the sulfur adversely affects sensor response, and could not be removed by exposure to hydrogen at the temperatures and pressures accessible in the ultrahigh vacuum experiments. Oxygen exposures, however, were very effective at removing sulfur, and the device performance after sulfur removal was indistinguishable from performance before exposure to $\mathrm{H}_{2} \mathrm{~S}$. 


\section{TABLE OF CONTENTS}

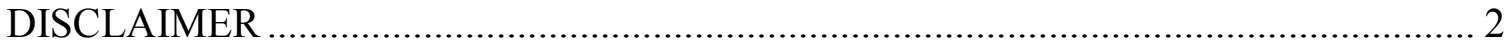

ABSTRACT .

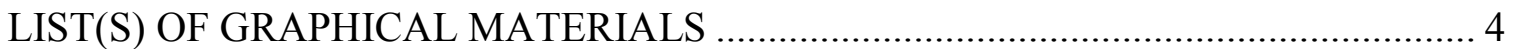

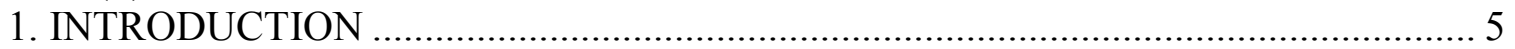

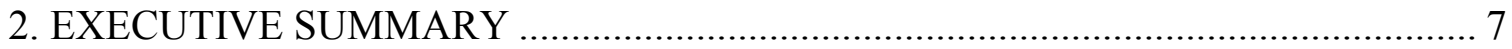

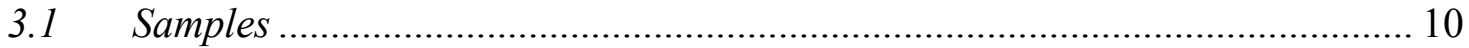

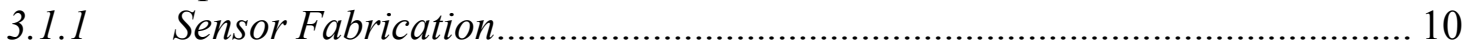

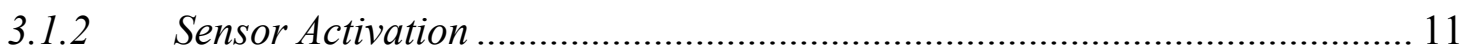

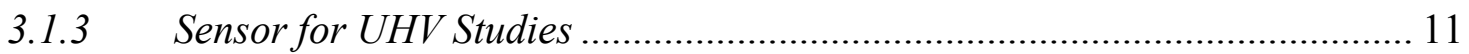

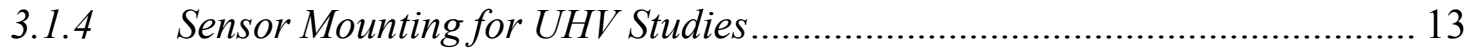

3.2 Design and Construction of "Nano-Reactor"................................................. 13

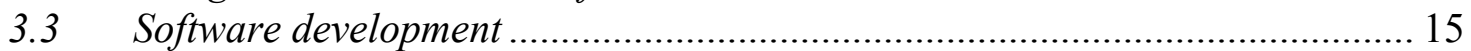

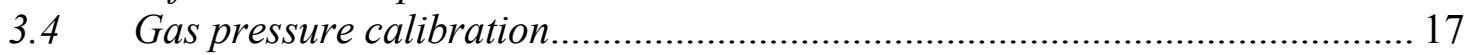

3.5 High Temperature Reliability of $\mathrm{SiC}$ n-MOS Devices up to $630{ }^{\circ} \mathrm{C}$.................. 18

3.5.1 Capacitance- voltage characterization ………............................................ 18

3.5.2 Gate reliability - oxide leakage measurements ........................................... 18

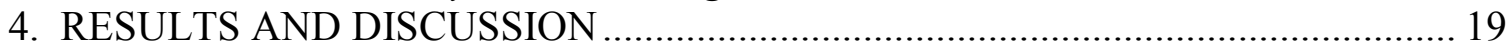

4.1 Effect of activation on sensor morphology and structure ................................ 19

4.2 Effect of activation on sensor sensitivity ........................................................ 22

4.3 Gate leakage measurements at high temperature............................................ 24

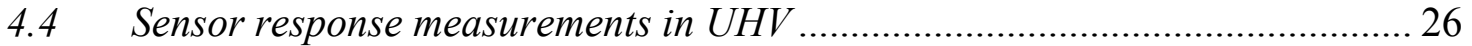

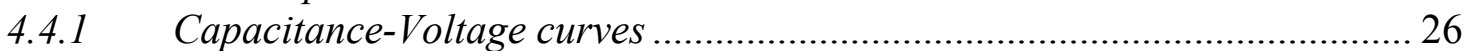

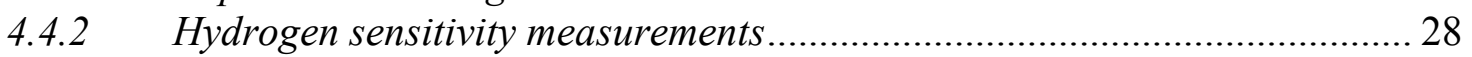

4.5 UHV studies of sulfur surface chemistry on the Pt gate …………................... 34

4.5.1 Sulfur deposition and coverage determination ............................................ 34

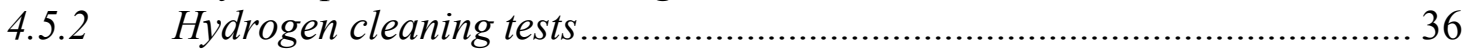

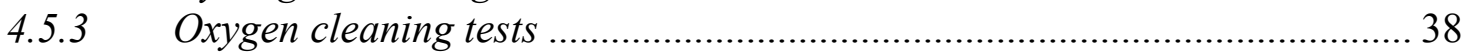

4.6.1 Typical stream compositions and conditions for one or more potential

applications for SiC based hydrogen gas sensors. ..................................................... 41

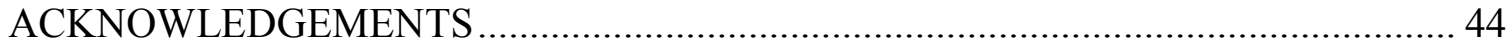

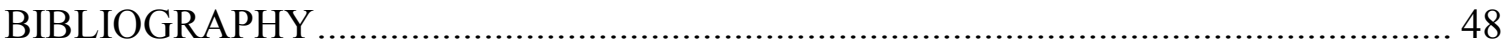

LIST OF ACRONYMS AND ABBREVIATIONS ..................................................... 49 


\section{$\underline{\text { LIST(S) OF GRAPHICAL MATERIALS }}$}

Fig. 1.1 Schematic of a $\mathrm{SiC}$ field-effect sensor for $\mathrm{H}_{2}$-containing gases 5

Fig. 1.2. High frequency $(1 \mathrm{MHz})$ capacitance-voltage characteristic of a $\mathrm{SiC} \quad 6$

Fig. 3.1.1.1: Photograph of a 6H-SiC sample with an array of $52 \mathrm{n}$-MOS devices $\quad 10$

Fig. 3.1.1.2 Resistive microheater assembly for high temperature sensor $\quad 10$

Fig. 3.1.3.1. Micrograph of the sample used in the UHV studies 11

Fig. 3.1.3.2. C-V curve shifts in oxygen and hydrogen, in UHV 12

Fig. 3.1.3.3. Temperature dependence of the sensor response 12

Fig. 3.2.3.1. Blueprint of the Nano-reactor" assembly at MSU. 14

Fig. 3.2.3.2. Photograph of the "Nano-reactor' assembly 14

Fig. 3.3.1. Front panel of the C-V scan program developed at Tufts. 15

Fig. 3.3.2. C-V curves measured in UHV. 16

$\begin{array}{ll}\text { Fig. 3.4.1. Calibration of RGA signal for hydrogen and oxygen. } & 17\end{array}$

Fig. 3.5.1.1: $1 \mathrm{MHz}$ capacitance-voltage characteristic of a capacitor. $\quad 18$

Fig. 4.1.1. High magnification micrographs of a few Pt gates before activation. 19

Fig. 4.1.2. A Dark field image of a $500 \mu \mathrm{m}$ in diameter Pt gate after activation. $\quad 20$

Fig. 4.1.3. X-ray diffraction scans of Pt sensing layers deposited on SiC. 21

Fig. 4.2.1: Sensor signal during device activation at $620^{\circ} \mathrm{C}$. 23

Fig. 4.3.1.: Gate leakage current as a function of voltage from $230-630^{\circ} \mathrm{C} \quad 24$

Fig.4.3.3. Temperature dependence of the gate leakage current density 25

Fig. 4.4.1.1. C-V shift measurement in hydrogen and oxygen. 26

Fig. 4.4.1.2. C-V curve shifts over time. $\quad 27$

Fig. 4.4.2.1. Sensor signal and gas pressures monitored during sensing tests. 29

Fig. 4.4.2.2. Voltage shift vs. hydrogen pressure 29

Fig. 4.4.2.3 Comparison of hydrogen response $\quad 30$

Fig. 4.4.2.4. Auger scans showing the cleaning effect of sensor measurements. $\quad 31$

Fig. 4.4.2.5. Sensor responses in UHV to hydrogen partial pressure changes $\quad 32$

Fig. 4.4.2.6. Sensor signal and gas pressures before and after $\mathrm{H}_{2} \mathrm{~S}$ dose. 33

Fig. 4.5.1.2. Sulfur coverage during contamination prevention tests. 35

Fig. 4.5.2.1. Effects of hydrogen exposure on sulfur coverage. 36

Fig. 4.5.2.1. Gas level and sensor signals during hydrogen cleaning tests. 37

Fig. 4.5.3.1. Effects of oxygen exposure on sulfur coverage. 39

Fig. 4.5.3.2. Gas level and sensor signals monitored during oxygen cleaning $\quad 40$

Fig. 4.5.3.3. Sensor responses to hydrogen partial pressure changes 40 


\section{INTRODUCTION}

Emissions control for the energy sector requires gas sensors that can operate in chemically reactive high temperature environments for both real time monitoring and feedback control of exhaust products. Gaseous species that need to be monitored include hydrogen, hydrocarbons, nitrogen oxides and sulfur oxides. Metal / insulator / semiconductor structures with catalytically active gates are widely used to electronically detect the presence of various chemical species [Spetz 2001]. The wide bandgap semiconductor silicon carbide, $\mathrm{SiC}$, enables device operation to temperatures in excess of $1200 \mathrm{~K}$. In the case of the $6 \mathrm{H}$ polytype the energy gap is $3.0 \mathrm{eV}$, compared to $1.1 \mathrm{eV}$ for silicon. These field-effect devices require a robust dielectric to enable modulation of the semiconductor carrier concentration via an applied gate potential. $\mathrm{SiC}$ has a native oxide, $\mathrm{SiO}_{2}$, which fulfills this need. In addition, $\mathrm{SiC}$ is chemically stable in reactive environments making it well suited for sensing applications in harsh environments.

Refractory metal gate $\mathrm{SiC}$ devices have been demonstrated for high temperature chemical sensing application by a number of groups [Spetz 2001, Filippov 1999, Hunter 2000, Kim 2001, Nakagomi 2001, Samman 2000, Serina 2001, Ghosh 2002]. These include hydrogen and hydrocarbon sensors operating at temperatures from $600 \mathrm{~K}$ to $1300 \mathrm{~K}$. Specific sensor configurations have achieved millisecond time response and sensitivity at the $0.1 \%$ level. The fast response makes the sensors suitable for feedback control. In addition, there are preliminary indications that suitably designed devices may offer sensitivity to ammonia, carbon monoxide, nitrogen oxides and fluorocarbons.

The operation of field-effect devices is dominated by electronic interactions at interfaces. In the case of a metal/insulator/SiC (MISiC) structure, these interfaces are the environment/metal interface, the metal/oxide interface and the oxide/semiconductor interface, which will be studied using a number of spectroscopic techniques. For the SiC sensor technology to fulfill its potential in real world applications the issues of reliability and stability need to be addressed, which requires a detailed experimental study of hydrogen transduction following dehydrogenation at the heated catalytic gate.

A schematic of our catalytic gate SiC field-effect sensor for hydrogen containing species is shown in Figure 1.1. Refractory metal gates such as Pt, Pd and Ir can efficiently dehydrogenate long chain hydrocarbons at temperatures above $700 \mathrm{~K}$. Following dehydrogenation at the heated gate, hydrogen diffuses into the structure.

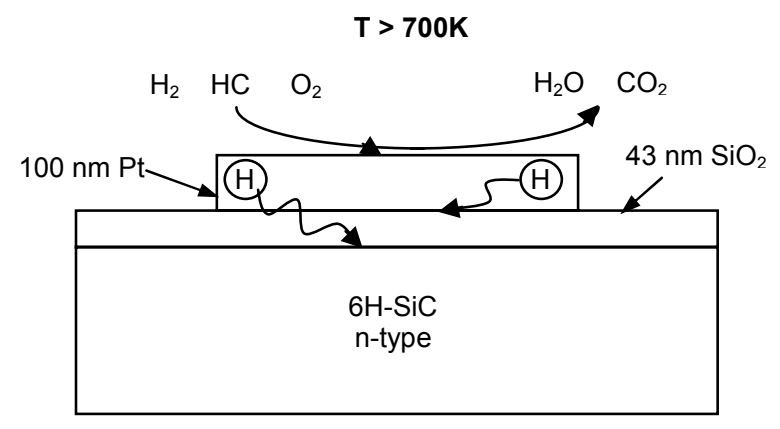

Fig. 1.1 Schematic of a catalytic gate SiC field-effect sensor for hydrogen containing gases. Typical operation is at $\mathrm{T}>700 \mathrm{~K}$. Hydrogen can diffuse to both the metal/oxide and oxide/semiconductor interfaces. 
For a Si-based catalytic gate sensor operating below $500 \mathrm{~K}$ it has been shown that hydrogen gives rise to a polarized layer at the metal/oxide interface [Lundstrom 1976]. This chemically induced polarization charge results in a simple lateral shift of the $\mathrm{C}-\mathrm{V}$ or current-voltage (I-V) characteristic of the capacitor or Schottky diode sensor, respectively. The magnitude of the voltage shift in these Si based sensors is a measure of the chemically modified metal/semiconductor barrier height.

It has been assumed that the same mechanism describes the operation of higher temperature $\mathrm{SiC}$ based sensors for hydrogen containing species. At temperatures above $700 \mathrm{~K}$ the diffusion time for hydrogen through $100 \mathrm{~nm}$ of $\mathrm{Pt}$ and $50 \mathrm{~nm}$ of $\mathrm{SiO}_{2}$ is less than $5 \mu$ s [Katsuta 1979] and $0.5 \mathrm{~ms}$ [Beadle 1985] respectively. We have previously demonstrated via in-situ $\mathrm{C}$-V spectroscopy of $\mathrm{Pt} / \mathrm{SiO}_{2} / \mathrm{SiC}$ sensors at $800 \mathrm{~K}$ that oxidizing species affect the electronic properties of both the metal/oxide and oxide/semiconductor interfaces [Tobias 2003A]. Fig. 1.2 shows that the C-V characteristic of the sensor in hydrogen is that of an ideal capacitor, within the uncertainty of the experiment. The effect of an oxidizing environment is two fold. First, the $\mathrm{C}-\mathrm{V}$ characteristic is shifted to more positive potentials, due to chemically induced change in the metal/semiconductor barrier height. Secondly the transition from accumulation to inversion is significantly broadened, indicating the presence of charged states at the oxide/semiconductor interface. Therefore, the mechanisms responsible for hydrogen transduction for $\mathrm{Pt} / \mathrm{SiO}_{2} / \mathrm{SiC}$ catalytic gate sensors are significantly more complex than that of the lower temperature Si based sensors.

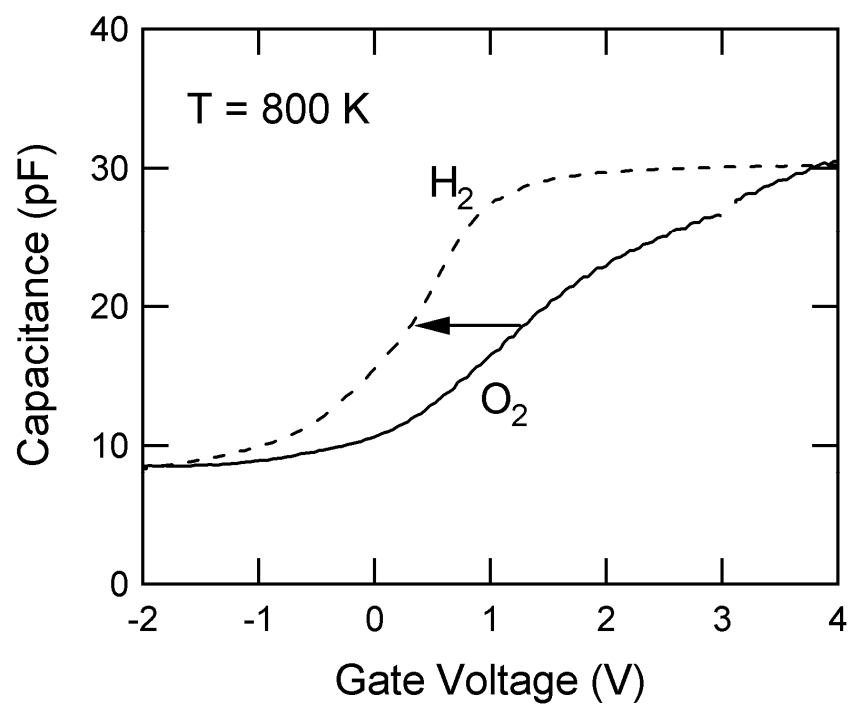

Fig. 1.2 High frequency $(1 \mathrm{MHz})$ capacitance - voltage characteristic of a $\mathrm{SiC}$ sensor at $800 \mathrm{~K}$ in $10 \mathrm{H}_{2}$ and $1 \% \mathrm{O}_{2}$ (balance gas is $\mathrm{N}_{2}$ ). To use the device as sensor, the capacitance is held fixed, while the voltage required to maintain that capacitance is recorded as the sensor signal.[Ghosh 2002]. 


\section{EXECUTIVE SUMMARY}

A silicon carbide ( $\mathrm{SiC}$ ) based sensor for the detection of power plant combustion products has been developed. The sensor is a catalytic gate field effect device that can detect hydrogen containing species in chemically reactive, high temperature environments.

A new sensor activation technique has been developed during this reporting period that provides a uniform activation environment for all $52 \mathrm{Pt}$ catalytic gates or sensor films on our $1 \mathrm{~cm}^{2}$ sensor chip. We use the term "activation" for the process that modifies the as-deposited Pt catalyst resulting in a sensor with fast and stable response to hydrogen-containing gases.

We have characterized the change in the gate surface morphology due to activation. In the characterization process, we collect both Bright-field (BF) and Darkfield (DF) images of a few gates, before and after the activation process. The BF images are useful in characterizing the surface morphology of the Pt gates before activation; the DF images before activation are featureless. However, the DF images are an excellent way to bring out the texturing of the Pt created during the activation. Prior to activation the catalyst surface is smooth and shiny, whereas a rough-cloudy surface is the common characteristic of activated Pt gates. The structure of the Pt gates was also investigated via $\mathrm{x}$-ray diffraction (XRD). Prior to activation we have a highly textured (111) fcc Pt film. Two additional peaks and a broad low angle background spectra are superimposed on top of the (111) peak after activation, suggestive of an amorphous phase on the surface.

We studied the high temperature reliability of our $\mathrm{SiC} \mathrm{n-MOS} \mathrm{sensor} \mathrm{structures}$ up to $630{ }^{\circ} \mathrm{C}$. Oxide leakage measurements were made on three $6 \mathrm{H}-\mathrm{SiC}$ samples subjected to different thermal stress cycles. The results from three samples after sequential heating at $330,430,540$ and $630{ }^{\circ} \mathrm{C}$, demonstrate that the continuous heating does not adversely affect the capacitors. The flat band voltage for all gates from these samples is close to theory. These results are very encouraging in terms of the long-term reliability of $\mathrm{SiC}$ field-effect sensors. It is especially promising that large area devices (1 $\mathrm{mm}$ diameter) have such low leakage current densities up to $630^{\circ} \mathrm{C}$, as the signal to noise ratio of the sensor increases with gate diameter. We attribute the high temperature performance of the dielectric in our sensor to the unique oxidation techniques developed by our collaborator Prof. John Williams at the Dept. of Physics, Auburn University. As Dr. Williams' group continues to improve the electrical quality of the $\mathrm{SiO}_{2}$ insulating layer, we are eager to strengthen our collaboration with him in order to fabricate reliable high temperature gas sensor devices suitable for long term continuous applications in a syngas environment.

We also have designed and built an operational sensor test system to simulate the gas temperature and flow rates encountered in the NETL micro-reactor. The new system, named the "nano-reactor," is compatible with the module developed in phase I for sensor testing under industrial conditions. The nano-reactor consists of: (i) An automated gas switching valve to switch between the oxidizer $\left(1 \% \mathrm{O}_{2}\right)$ and a reducer $\left(52 \mathrm{ppm}\right.$ to $10 \% \mathrm{H}_{2}$ is currently available, we have ordered $50 \% \mathrm{H}_{2}$ ); (ii) Two thermometers to record and control the temperature in the gas chamber and the area surrounding the sensor; (iii) A high temperature gas chamber for pre-heating the flowing gas up to $1000{ }^{\circ} \mathrm{C}$; (iv) A stainless-steel union to couple the reactor to the high temperature test module, which was 
used in phase I during testing at NETL; (v) A heater strip to heat and keep the pre-heated gas at a desired temperature. The system also has the valves, flow-meter, and a pressure gauge for high-pressure operation including two one-way valves and a flow meter for regulation of both pressure and the flow rate $(0-1000 \mathrm{sccm})$.

Ultrahigh vacuum (UHV) surface chemistry experiments can be an invaluable complement to standard experiments carried out near atmospheric pressure. Although the gas pressures and flow rates differ by orders of magnitude between the two types of study, decades of experience in catalytic surface chemistry have shown that UHV experiments can probe the same fundamental reaction and transduction mechanisms, under similar conditions of surface and interface coverage and similar ratios of the relevant reactant gases. Further, the control of gas exposure and surface sensitive spectroscopies available in the UHV environment allow detailed mechanistic investigations that are not possible at higher pressures. In the case of the silicon-based MOS gas sensors that are the prototype for the MISiC sensors studied here, UHV experiments provided valuable insights into the fundamental processes of sensor operation [Petersson 1985, Eriksson 1997]. To our knowledge, there have been no prior studies of MISiC sensor operation under UHV conditions.

In Phase I we reported a number of difficulties with the UHV sensor measurements, including unexplained device failures and anomalously low device sensitivity. In the current period many of these obstacles were overcome. Reliable and reproducible sensing has been demonstrated over months of repeated temperature cycling, with sensitivities comparable to those obtained at ambient pressures. Exposure of the device to charged particles for ion sputter cleaning and Auger electron spectroscopy did not cause any damage, making it possible to use the full range of surface analysis tools on working sensor gates. These improvements resulted from: (1) Using a chip fabricated using the same process that produced the most reliable sensors in atmospheric pressure testing; (2) Gate activation at ambient pressure at MSU prior to use in UHV at Tufts; and (3) Improved methods of sample mounting.

Because sulfur compounds are common contaminants in realistic gas streams, and well-known poisons for catalysts, we have carried out a detailed study of sulfur contamination of the gate surface in UHV. Hydrogen sulfide readily deposits sulfur on the gate surface even at extremely low pressures $\left(\sim 10^{-11}\right.$ Torr $)$, and even in the presence of much higher concentrations of hydrogen (as much as $10^{5}$ times higher than the $\mathrm{H}_{2} \mathrm{~S}$ pressure). The sulfur has a significant adverse effect on the sensor's sensitivity to hydrogen. Exposure of the contaminated surface to hydrogen at temperatures up to 900 $\mathrm{K}\left(630^{\circ} \mathrm{C}\right)$ did not significantly reduce the amount of sulfur on the surface. Exposure to oxygen, however, was very effective at removing sulfur. These results suggest that sulfur contamination may be a significant issue for device operation, but that it can be minimized by periodic exposure to oxygen.

In consultation with Susan Maley we identified typical stream compositions and conditions for potential applications for our $\mathrm{SiC}$ based hydrogen gas sensor. These include monitoring the gas stream in a syngas application and in the "Cold gas cleaning process" of integrated gasification combined cycle (IGCC) gasifiers.

From a project management perspective, Dr. Yung Ho Kahng who joined the project as a postdoctoral associate in July 2004, working on the UHV experiments is continuing with the effort into Phase II. Dr. Reza Loloee, a Research Specialist with the 
Dept. of Physics at Michigan State University, who joined the effort in March 2005, is also continuing with the effort into Phase II.

During this reporting period we have made a number of presentations at international meetings. A poster entitled: "High Temperature Reliability of SiC n-MOS Devices up to $630^{\circ} \mathrm{C}$ " by Ruby N. Ghosh, Reza Loloee, Peter Tobias, Tamara IsaacsSmith and John R. Williams was presented at the International Conference of Silicon Carbide and Related Materials, Pittsburgh, PA, Sept. 18-23, 2005. This material will appear in a peer reviewed publication in 2006 [Ghosh 2006]. . A poster was presented at the 2005 Annual Symposium of the American Vacuum Society, Boston, MA, Oct. 31Nov. 4, 2005 on "UHV studies of silicon carbide gas sensors with catalytic platinum gates" by Y.H. Kahng, R.G. Tobin and R.N. Ghosh. At the 2005 IEEE International Conference on Sensors, Irvine, CA, Oct. 31 - Nov. 3, 2005 we presented a talk on "Performance of Silicon Carbide High Temperature Gas Sensors" by Reza Loloee and Ruby N. Ghosh and a poster on "Fast solid state gas sensor characterization technique with millisecond resolution", by Ruby N. Ghosh and Peter Tobias. Both of these two presentations will appear as short papers in the 2005 IEEE Sensors conference proceedings.

Ruby Ghosh served as the America's co-chair of the Technical Program Committee of the 2005 IEEE International Conference on Sensors in Irvine, CA, Oct. 31 - Nov. 3, 2005 (http://www.ieee.org/sensors2005). She was responsible for arranging the reviewing of 100 abstracts and organized the technical sessions. In addition she presented two seminars at industrial labs on "Silicon carbide high temperature gas sensors" at the Ford Research Laboratory, Dearborn, MI, on Aug. 30, 2005 and "The challenges of long-term continuous operation of $\mathrm{SiC}$ devices at high temperature" at the General Electric Corporate Research \& Development Center in Niskayuna, NY on Feb. 16, 2006. 


\section{EXPERIMENTAL}

\subsection{Samples}

\subsubsection{Sensor Fabrication}

The n-MOS capacitors were fabricated on $6 \mathrm{H}-\mathrm{SiC}$ substrates $\left(3 \mu \mathrm{m}, 2.1 \times 10^{16}\right.$ $\mathrm{N} / \mathrm{cm}^{3}$ epitaxial layer) and $4 \mathrm{H}-\mathrm{SiC}$ substrates $\left(10 \mu \mathrm{m}, 1.7 \times 10^{16} \mathrm{~N} / \mathrm{cm}^{3}\right.$ epitaxial layer). The gate oxide $(\sim 39 \mathrm{~nm})$ was grown via dry oxidation at $1150{ }^{\circ} \mathrm{C}$, followed by a $900{ }^{\circ} \mathrm{C}$ $\mathrm{Ar}$ anneal and a 2 hour $1175^{\circ} \mathrm{C} \mathrm{NO}$ anneal. The gate metal is $100 \mathrm{~nm}$ of Pt sputtered at $350^{\circ} \mathrm{C}$ in a 5 mTorr Ar atmosphere. As shown in Fig. 3.1.1.1, each sample consists of an array of 52 gates with nominal diameters of 200 to $1000 \mu \mathrm{m}$. The noise in our electrical characterization system is $\pm 2 \mathrm{pA}$ for the current-voltage (I-V) measurements and is $\pm 2 \mathrm{pF}$ for capacitance-voltage $(\mathrm{C}-\mathrm{V})$ measurements, all at $630^{\circ} \mathrm{C}$.

Fig. 3.1.1.1: Photograph of a $6 \mathrm{H}-\mathrm{SiC}$ sample $(1 \mathrm{~cm} \mathrm{x}$ $1 \mathrm{~cm})$ with an array of $52 \mathrm{n}-\mathrm{MOS}$ devices mounted on an alumina header. Nominal gate diameters are: 200, 300, 500 and $1000 \mu \mathrm{m}$.

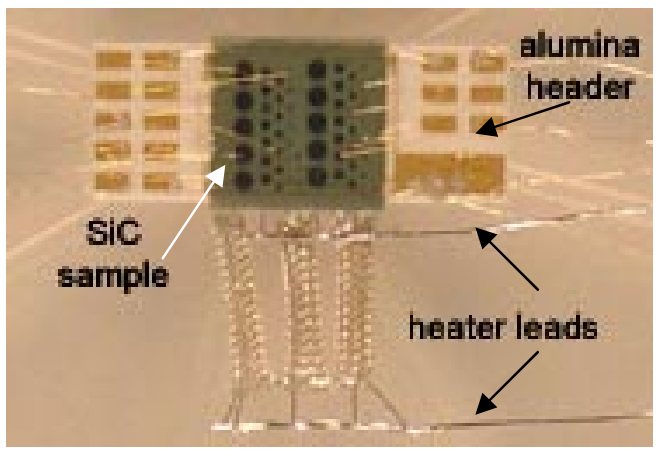

As shown in the previous report and repeated here, for the atmospheric sensor measurements we heat the $\mathrm{SiC}$ sensor chip locally via three Pt microheaters that are thermally attached to the back of the alumina header (see Fig. 3.1.1.2)

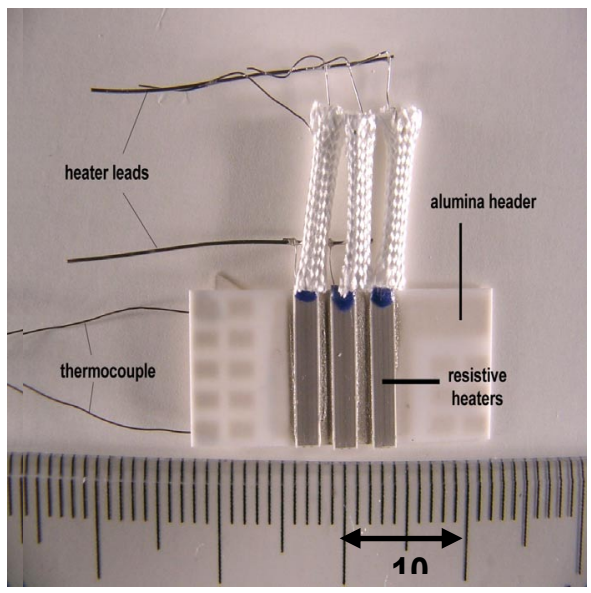

Fig.3.1.1.2 Resistive microheater assembly for high temperature sensor measurements under atmospheric conditions. Shown is the back of the alumina header with heater assembly, which allows heating the $\mathrm{SiC}$ sample to $670{ }^{\circ} \mathrm{C}$. The electrical connections for heaters and thermocouple are made with a microwelder. Positive and negative voltages are separated by silica insulating tubing. 


\subsubsection{Sensor Activation}

Activation of $\mathrm{SiC}$ gas sensors takes place by switching between oxidizing and reducing gases, to obtain a fast and stable sensor response. All the devices of a n-type $6 \mathrm{H}-\mathrm{SiC}$ sensor chip or $4 \mathrm{H}-\mathrm{SiC}$ sensor chip were activated simultaneously by flooding the entire chip with gas at $620{ }^{\circ} \mathrm{C}$. In the activation process, alternately, $1.0 \% \mathrm{O}_{2}$ and $10 \%$ $\mathrm{H}_{2}$ are sprayed onto the entire face of the SiC chip, which is heated by the micro heaters. The signal from one of the sensors - typically a $1 \mathrm{~mm}$ diameter device - is monitored during the activation process. The sensor measurements were made by monitoring the gate voltage, while holding the capacitance fixed at midgap bias.

\subsubsection{Sensor for UHV Studies}

We prepared a new sample, $\mathrm{SiC} 7+\mathrm{I}+\mathrm{I}$, for use in UHV studies of gate surface chemistry and sensor performance. This sample had 52 gates with nominal diameters of 200, 300, 500, and $1000 \mu \mathrm{m}$ and was prepared as described in section 3.1.1. A micrograph of the wire-bonded top surface of the sample is shown in Fig. 3.1.3.1. Prior to installation in UHV the sample was activated at MSU as described in section 3.1.2. Micrographs clearly showed roughening of the gate surface, as discussed in section 4.1.

The sample was extensively characterized under atmospheric pressure conditions at MSU, to establish a baseline for comparison with the UHV results. Fig. 3.1.3.2 shows $\mathrm{C}-\mathrm{V}$ curves in $10 \%$ hydrogen and $1 \%$ oxygen, at $778 \mathrm{~K}\left(505^{\circ} \mathrm{C}\right)$ before and after activation, showing the increase in sensitivity due to activation. Fig. 3.1.3.3 shows the sensor response as a function of operating temperature.

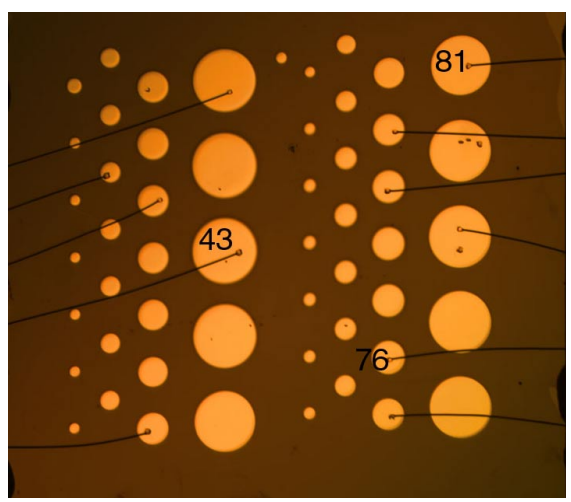

Fig. 3.1.3.1. Micrograph of the sample used in the UHV studies, SiC7+I+I. Eleven gates were wire-bonded by gold wires for the sensor measurements. Marked gates 43, 76 , and 81 were initially connected to the outside. The rest of the wire-bonded gates were grounded. All the UHV sensor measurements included in this report were carried out on gate 43 . 


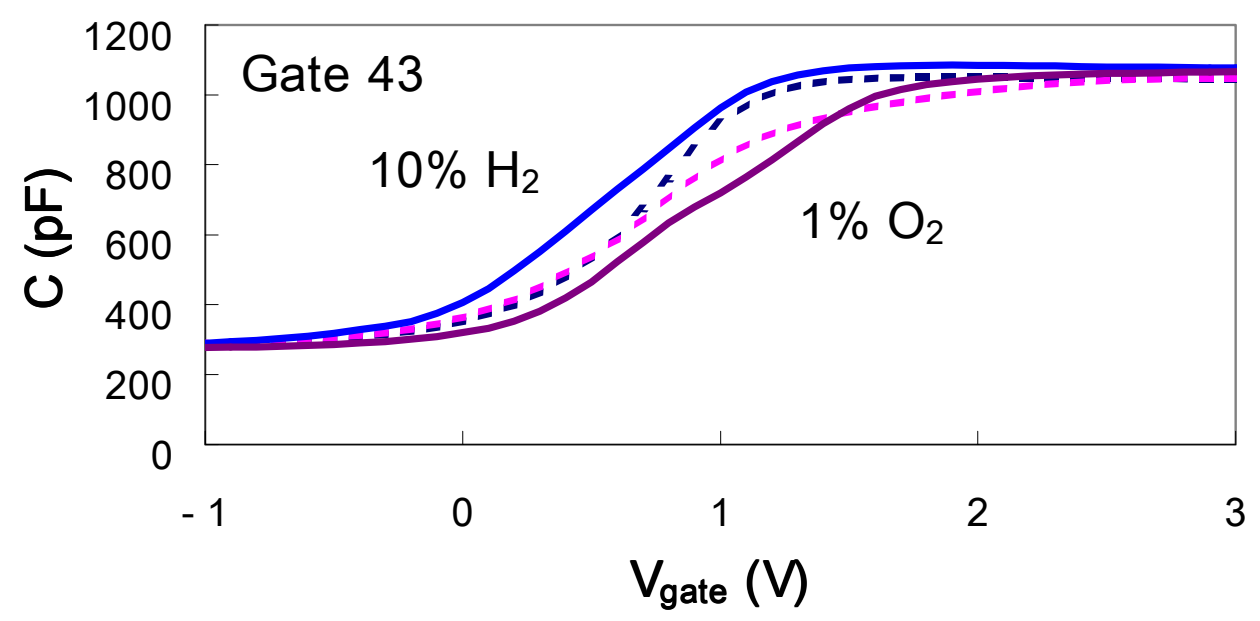

Fig. 3.1.3.2. $1 \mathrm{MHz} \mathrm{C}-\mathrm{V}$ characteristics in oxygen and hydrogen of gate 43 before and after activation, measured under atmospheric conditions. Left two curves were measured in $10 \%$ hydrogen, and right two curves were measured in $1 \%$ oxygen. Dashed/solid curves were measured before/after the activation. Measurements were done at $778 \mathrm{~K}$.

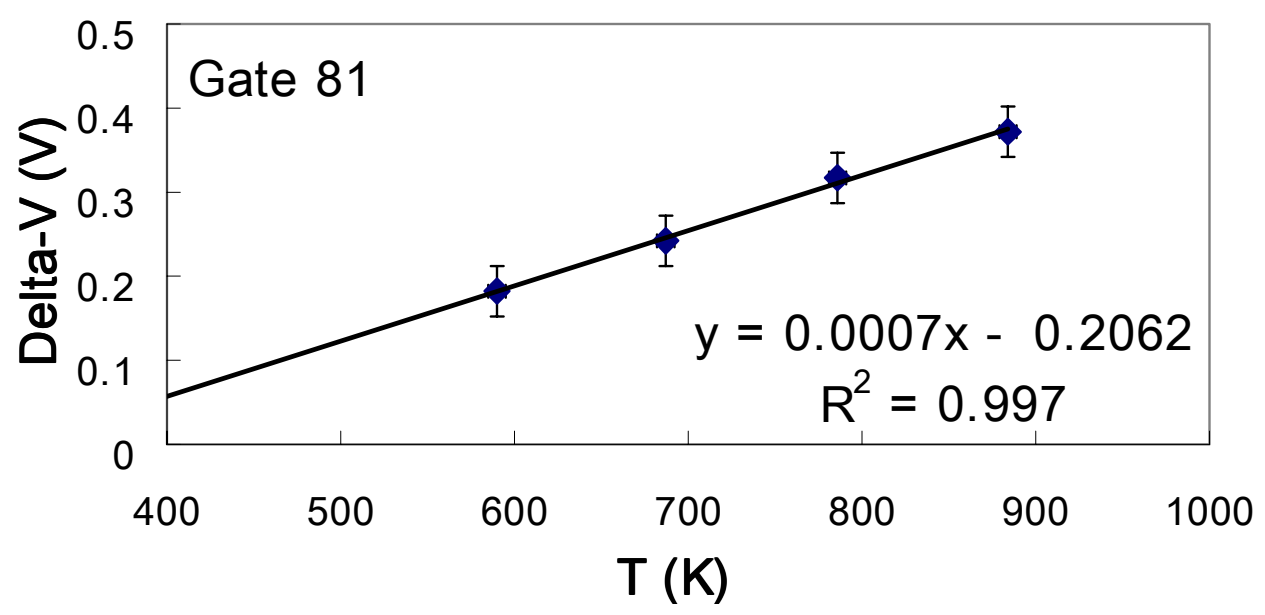

Fig. 3.1.3.3. Temperature dependence of the sensor response $\left(10 \% \mathrm{H}_{2}\right.$ vs. $\left.1 \% \mathrm{O}_{2}\right)$ measured under atmospheric conditions. The signal response increased with temperature at a $0.7 \mathrm{mV} / \mathrm{K}$ rate. 


\subsubsection{Sensor Mounting for UHV Studies}

In Phase I we reported a pattern of device failure during UHV measurements, and speculated that charged particles - used for ion sputter cleaning, Auger electron spectroscopy, and sample heating - might have been causing damage to the oxide layer. This hypothesis, if correct, would have seriously limited our ability to use standard surface analysis techniques on working devices. Testing of the "failed" samples, however, revealed that most of the problems were in fact due to failures of the electrical contacts between the device and its mounting header. When reattached, some of the failed samples exhibited $\mathrm{C}-\mathrm{V}$ characteristics similar to their original curves.

We have now developed improved mounting techniques, including the use of back metallization on the SiC chip, better silver paint (GC Electronics, Silver Print II), and a more careful mounting procedure. Mounted in this way, the new sample (see section 3.1.3) has been repeatedly cycled to temperatures as high as $900 \mathrm{~K}\left(630^{\circ} \mathrm{C}\right)$ and exposed to ion and electron beams without degradation.

\subsection{Design and Construction of "Nano-Reactor"}

We have designed and built an operational sensor test system to simulate the gas temperature and flow rates encountered in the NETL micro-reactor. The new system "nano-reactor" is compatible with the module developed in phase I for sensor testing under industrial conditions. As shown in Fig. 3.2.3.1. the nano-reactor contains:

1) An automated gas switching valve to switch between the oxidizer $\left(1 \% \mathrm{O}_{2}\right)$ and a reducer (52 ppm to $10 \% \mathrm{H}_{2}$ are currently available, $50 \% \mathrm{H}_{2}$ is on order).

2) Two thermometers to observe and control the temperature in the Gas chamber and the sensor surrounding area.

3) High Temperature gas chamber, able to pre-heat the flowing gas up to $1000{ }^{\circ} \mathrm{C}$.

4) A stainless-steel union coupled to the gas-heating chamber and capable of accepting the high temperature test module (used in phase I at NETL).

5) A heater strip to heat and keep the pre-heated gas at a desired temperature.

6) This system also contains two valves, a flow-meter, and a pressure gauge for high-pressure operation.

7) Two one-way valves and a flow meter capable to regulate both pressure and the flow rate $(0-1000 \mathrm{sccm})$.

A photograph of the main body of the nano-reactor is shown in Fig. 3.2.3.2. 


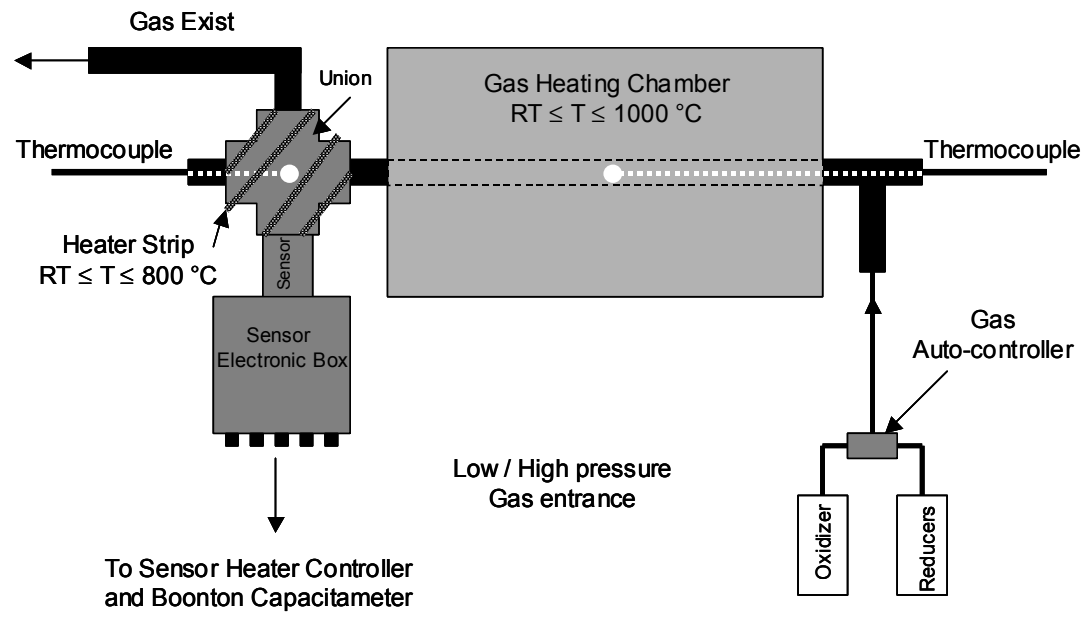

Fig. 3.2.3.1 Blueprint of the Nano-reactor" assembly for sensor measurements at MSU. The thermocouples for monitoring the gas temperature are inserted from both ends: One from the left into the union cross and the second one from the right into the gas heating oven. The gas temperature will vary from 85 to $700{ }^{\circ} \mathrm{C}$. The sensor chip will be maintained at $\sim 620{ }^{\circ} \mathrm{C}$ for fast response. The coaxial connectors are rated for continuous operation at $200{ }^{\circ} \mathrm{C}$.

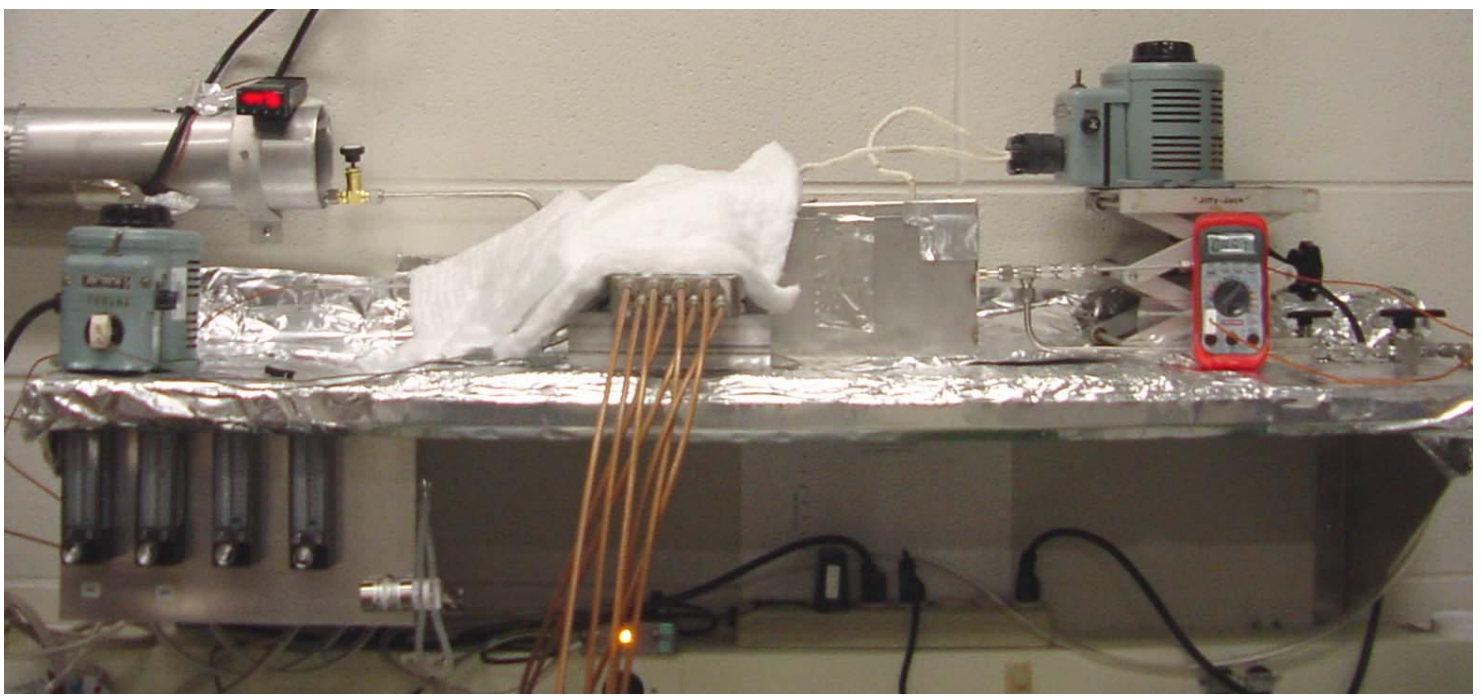

Fig. 3.2.3.2 Photograph of the "Nano-reactor' assembly with the electrical breakout box and other accessories. 


\subsection{Software development}

We have developed a new LabView program for measuring capacitance-voltage $(\mathrm{C}-\mathrm{V})$ curves in UHV, using the Boonton capacitance meter. Fig. 3.3.1 shows the front panel of the program. The left panel of Fig. 3.3.2 shows C-V curves measured in UHV with this program during hydrogen and oxygen exposures. For comparison, $\mathrm{C}-\mathrm{V}$ curves measured on an earlier sample, which had not been activated at atmospheric pressure prior to the UHV measurements, are shown in the right panel. The much larger sensor response of the fully activated sample is apparent. The sensor response is discussed more fully in section 4.4 .

In addition to being a valuable tool in its own right, this $\mathrm{C}-\mathrm{V}$ program represents the first step toward developing an integrated program that performs all the necessary tasks needed for sensor operation in UHV: C-V curve scan, sensor signal measurement, and temperature control. The next step will be to integrate active temperature regulation into the system, using a newly acquired analog interface to control our existing heating system.

UHV sensor measurements reported in Phase I were carried out under constantbias-voltage conditions. For those measurements, on devices that had not been fully activated, constant-voltage measurements were adequate, because the $\mathrm{C}-\mathrm{V}$ shifts were so small. For the larger shifts encountered on fully activated sample, a feedback system is needed to operate under constant-capacitance conditions. We have now identified optimal settings for the feedback program, and are using it successfully for constantcapacitance measurements. All UHV sensor response measurements in this report were made under constant capacitance conditions, with the device biased near mid-gap.

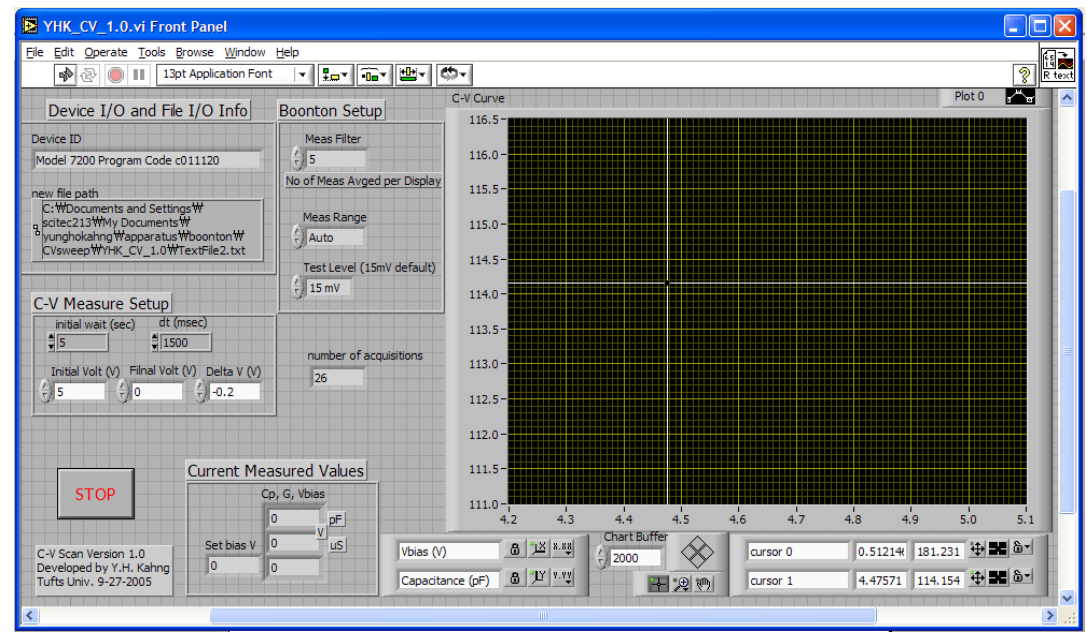

Fig. 3.3.1. Front panel of the C-V scan program developed at Tufts. 

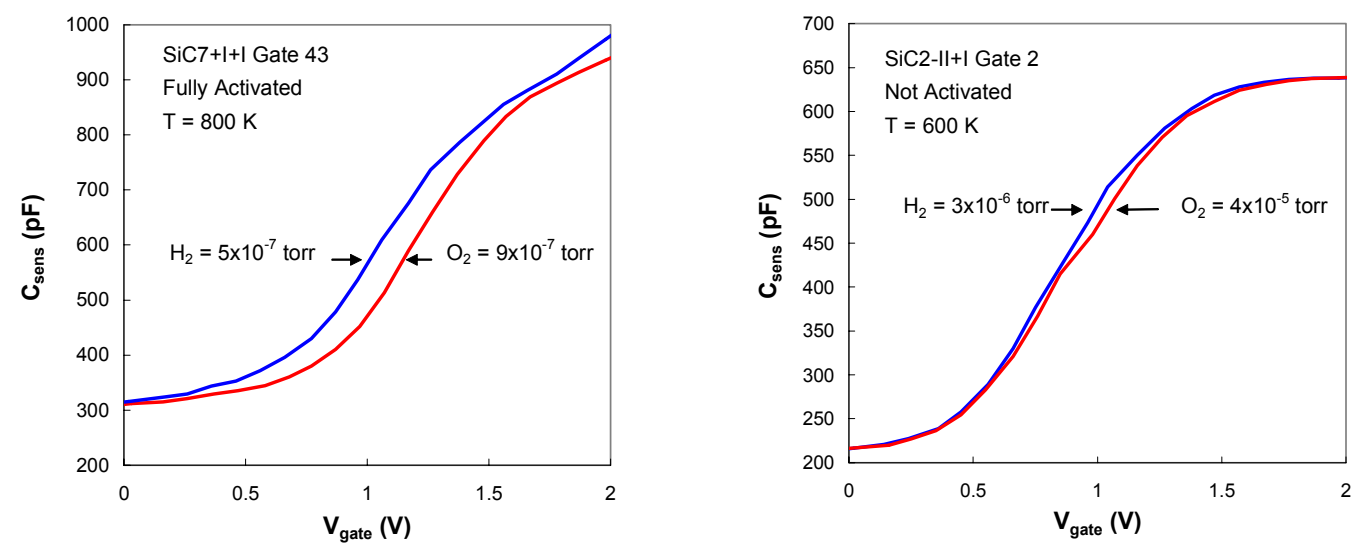

Fig. 3.3.2. $1 \mathrm{MHz} \mathrm{C}-\mathrm{V}$ curves measured in UHV. Left panel: New sample, fully activated at atmospheric pressure before installation in UHV, measured with new LabView program. Right panel: Previous sample, not activated at atmospheric pressure, measured with earlier (Asyst) program. The fully activated sample shows a much larger voltage shift. 


\subsection{Gas pressure calibration}

Measurements of gas partial pressure in UHV are based on ion current measurements from a quadrupole residual gas analyzer (RGA) (Balzers Prisma 200). Because of differences in molecular mass and ionization efficiency, the sensitivity of the RGA can be different for different gases. To obtain more accurate measurements of gas partial pressure, we calibrated the RGA signals against the ion gauge total pressure reading. Ion gauge pressure readings were corrected for different gas species' sensitivity [Summers 1969]. The ratio of true pressure to RGA signal was 0.4 for hydrogen and 1 for oxygen. Fig. 3.4.1 shows the calibration results for hydrogen and oxygen. This method could not be used for hydrogen sulfide, because the pressure of other gases was always greater than that of the $\mathrm{H}_{2} \mathrm{~S}$, due to chemical interactions in the vacuum pumps and on the chamber walls. All that could be determined was that for $\mathrm{H}_{2} \mathrm{~S}$ the RGA reading and actual partial pressure are consistent within an order of magnitude.
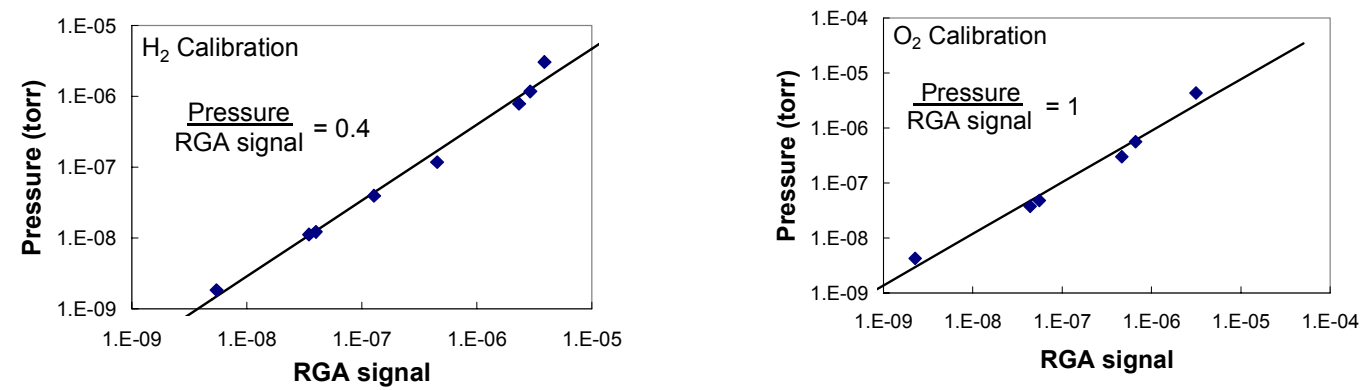

Fig. 3.4.1. Calibration of RGA signal against actual pressure for hydrogen and oxygen. 


\subsection{High Temperature Reliability of SiC n-MOS Devices up to $630^{\circ} \mathrm{C}$}

\subsubsection{Capacitance-voltage characterization}

We have used high frequency capacitance - voltage measurements extensively to characterize the electrical properties of the $\mathrm{SiC}$ MOS capacitors. The $1 \mathrm{MHz} \mathrm{C}-\mathrm{V}$

characteristic of a $1000 \mu \mathrm{m}$ diameter n-MOS capacitor at $330{ }^{\circ} \mathrm{C}$ is shown in Fig. 3.5.1.1. We operate the $\mathrm{Pt}_{-} \mathrm{SiO}_{2}-\mathrm{SiC}$ devices as sensors for hydrogen containing gases in the 400 $600{ }^{\circ} \mathrm{C}$ range. The optimum sensor bias point with respect to response time and device to device repeatability is near mid-gap [Ghosh 2002].

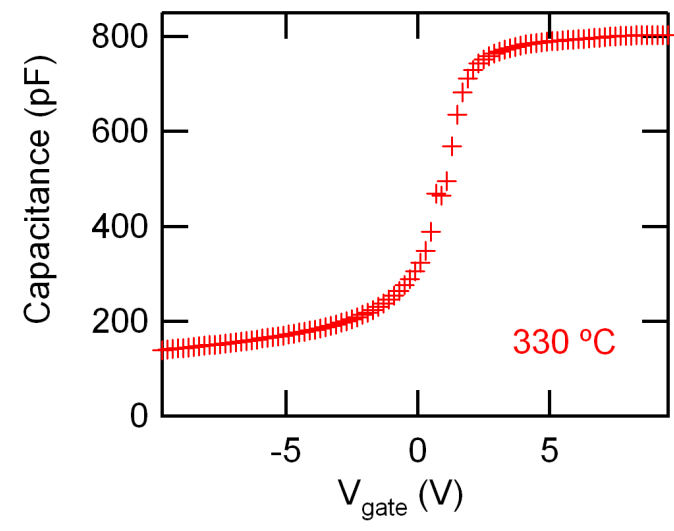

Fig. 3.5.1.1: $1 \mathrm{MHz}$ capacitance-voltage characteristic of a $1 \mathrm{~mm}$ diameter $6 \mathrm{H}-$ $\mathrm{SiC}$ n-MOS capacitor. For gas sensing the optimum device bias is at mid-gap.

\subsubsection{Gate reliability - oxide leakage measurements}

The gate leakage measurements were made in air using a commercial current voltage characterization system' consisting of a Keithley 236 Source Measurement unit and the Interactive Characterization Software (Metrics). The samples were placed inside a shielded probe station with a temperature controlled chuck that can be heated up to 320 ${ }^{\circ} \mathrm{C}$. To make $\pm 2 \mathrm{pA}$ measurements at high temperature, care was taken to electrically isolate the $\mathrm{SiC}$ sample mounted on its alumina header from the heater coils of the hot chuck. At a given temperature both a current - voltage (I-V) and capacitance - voltage $(1 \mathrm{MHz} \mathrm{C}-\mathrm{V})$ scan were taken for each device. The gate leakage characteristic as a function of gate voltage was obtained by subtracting out the "probe up" current from the $\mathrm{I}-\mathrm{V}$ characteristic. The leakage current density was evaluated at a gate voltage corresponding to the capacitor being biased at midgap as follows. First, we calculated the midgap capacitance from the measured device area, oxide thickness and doping density of the epitaxial layer (obtained from $1 / \mathrm{C}^{2}$ analysis of the $\mathrm{C}-\mathrm{V}$ curve in depletion). Then using the measured $\mathrm{C}-\mathrm{V}$ characteristic, we obtained the midgap voltage. 


\section{RESULTS AND DISCUSSION}

\subsection{Effect of activation on sensor morphology and structure}

We have characterized the change in the gate surface morphology due to surface activation processes. In the characterization process, we collect both Bright-field (BF) and Dark-field (DF) images of a few selected gates; before and after activation. BF images are convenient to demonstrate the surface morphology of the Pt gates before activation. DF images of smooth and shiny surfaces are featureless, but provide an excellent way to bring out the texture from rough surfaces created during the activation process. The left hand side image shown in Fig. 4.1.1 is the BF images of 3.5 gates (2 bonded) and on the right hand side, the DF images from the same area of non-activated gates is illustrated.
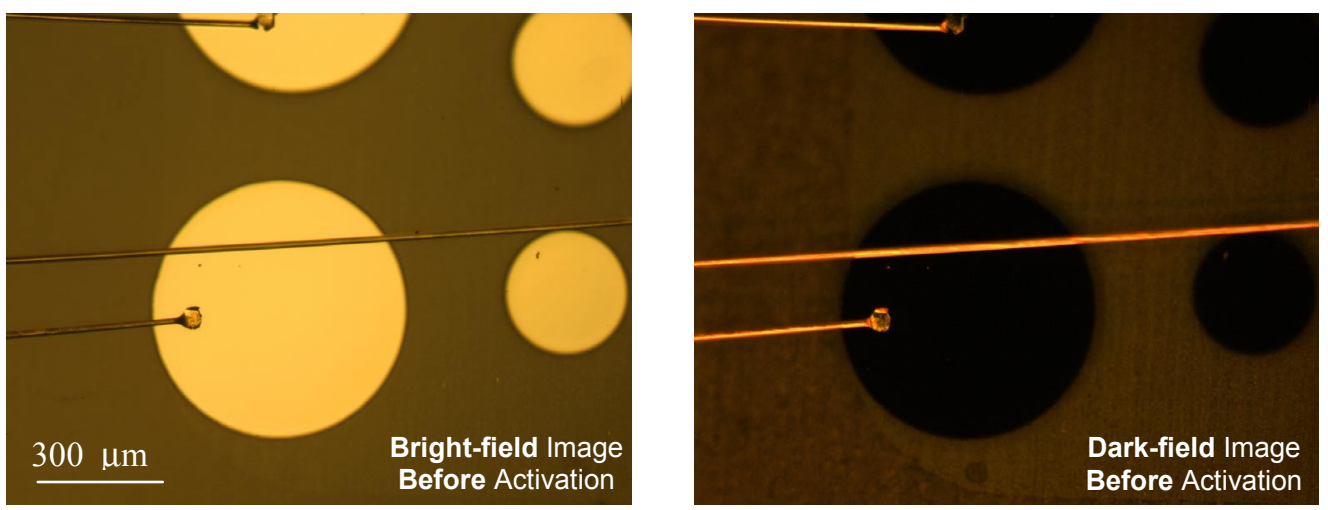

Fig. 4.1.1. High magnification micrographs of a few Pt gates before activation. The left image shows the BF image of the gates and the right image shows the DF image of the same gates. As the Pt surface is mirror smooth and shiny prior to activation, the DF image is featureless.

Shown in Fig. 4.1.2 is a DF image of a $500 \mu \mathrm{m}$ gate after activation. The gate morphology has changed to a textured surface morphology that is opaque (cloudy), i.e. no longer perfectly reflective in the visible. This image is typical for the majority of our activated Pt gates. Note that in some cases, the area around the bonded gold wire has a different surface morphology from that of the rest of gate. We postulate that direct bonding to the Pt gate may change the crystal structure of the point of contact as well as producing a strain in the area surrounding the point contact, which in turn depends on the specifics of the bonding parameters. 


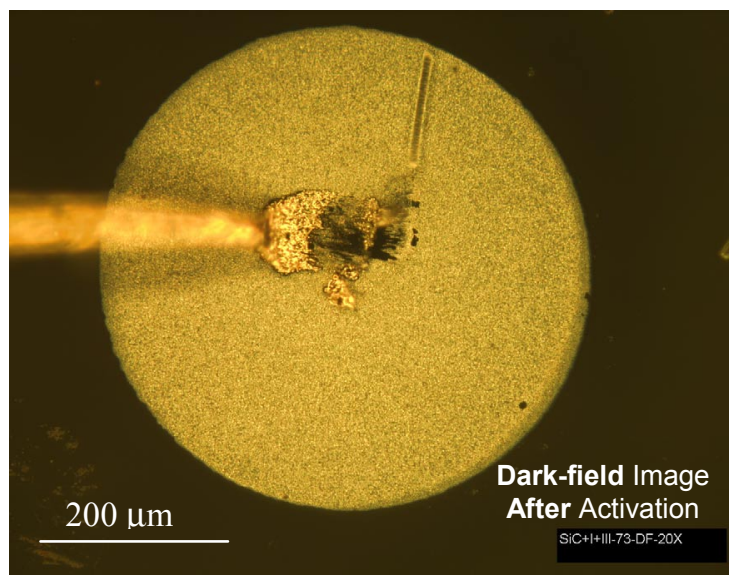

Fig. 4.1.2. A Dark field image of a $500 \mu \mathrm{m}$ in diameter Pt gate after activation. The Pt surface is now grainy (textured) and non-reflective, whereas it was shiny and featureless prior to activation (see Fig.4.1.1).

The structure of the $\mathrm{Pt}$ gates was investigated by collecting $\mathrm{x}$-ray diffraction (XRD) patterns before and after activation process. The XRD pattern from the Pt gates before activation is shown in Fig. 4.1.3a. As seen in the figure we observe only the Pt (111) peak at $2 \theta \cong 39.7^{\circ}$, the $\mathrm{Pt}(002)$ peak at $2 \theta \cong 46.2^{\circ}$ was not seen. This indicates that the Pt film is textured Pt (111). In Fig. 4.1.3b, shown is the XRD pattern collected from an activated gate. Three peaks (1-3) appeared in this XRD pattern with Pt (111) (\#2 at $2 \theta$ $\cong 39.7^{\circ}$ ) as the dominant peak. The spectrum has a higher background below $39.7^{\circ}$, suggestive of an amorphous material on the surface. There are two additional small peaks, (1) at $2 \theta \cong 38^{\circ}$ and (3) at $2 \theta \cong 44^{\circ}$. The lattice parameters of peaks $1 \& 3$ (see Table 4.1.1) do not match the first or higher order orientations of $\mathrm{Pt}, \mathrm{PtO}$ and $\mathrm{PtO}_{2}$. Note that the after activation XRD spectra were taken on a gate that had a bonded $\mathrm{Au}$ wire. The $\mathrm{Au}$ (111) peak is at $2 \theta \cong 38.11^{\circ}$ and the (002) peak is at $2 \theta \cong 44.29^{\circ}$, therefore we attribute peaks 1 and 3 to residual gold from the wire bonding processes.

\begin{tabular}{|c|c|c|c|}
\hline$(\mathrm{h}, \mathrm{k}, \mathrm{l})$ & Pt- $\mathrm{d}_{\mathrm{hkl}}(\AA) \Leftrightarrow 2 \theta$ & $\mathrm{PtO}-\mathrm{d}_{\mathrm{hkl}}(\AA) \Leftrightarrow 2 \theta$ & $\mathrm{PtO}_{2}$-dhkl $(\AA) \Leftrightarrow 2 \theta$ \\
\hline 001 & ---- & --- & $4.342 \Leftrightarrow 20.43^{\circ}$ \\
\hline 100 & ---- & $3.077 \Leftrightarrow 29^{\circ}$ & $2.696 \Leftrightarrow 33.19^{\circ}$ \\
\hline 002 & $1.962 \Leftrightarrow 46.2^{\circ}$ & $2.670 \Leftrightarrow 33.52^{\circ}$ & $2.171 \Leftrightarrow 41.54^{\circ}$ \\
\hline 101 & ---- & $2.666 \Leftrightarrow 33.57^{\circ}$ & ---- \\
\hline 110 & --- & $2.176 \Leftrightarrow 41.45^{\circ}$ & $1.556 \Leftrightarrow 59.32^{\circ}$ \\
\hline 111 & $2.266 \Leftrightarrow 39.73^{\circ}$ & ---- & $1.465 \Leftrightarrow 63.42^{\circ}$ \\
\hline 200 & ---- & $1.538 \Leftrightarrow 60.08^{\circ}$ & $1.348 \Leftrightarrow 69.67^{\circ}$ \\
\hline 202 & $1.387 \Leftrightarrow 67.44^{\circ}$ & $1.333 \Leftrightarrow 70.57^{\circ}$ & --- \\
\hline
\end{tabular}

Table 4.1.1 X-ray diffraction parameter for $\mathrm{Pt}, \mathrm{PtO}$ and $\mathrm{PtO}_{2}$ from [EMC] and [McBride 1991]. 

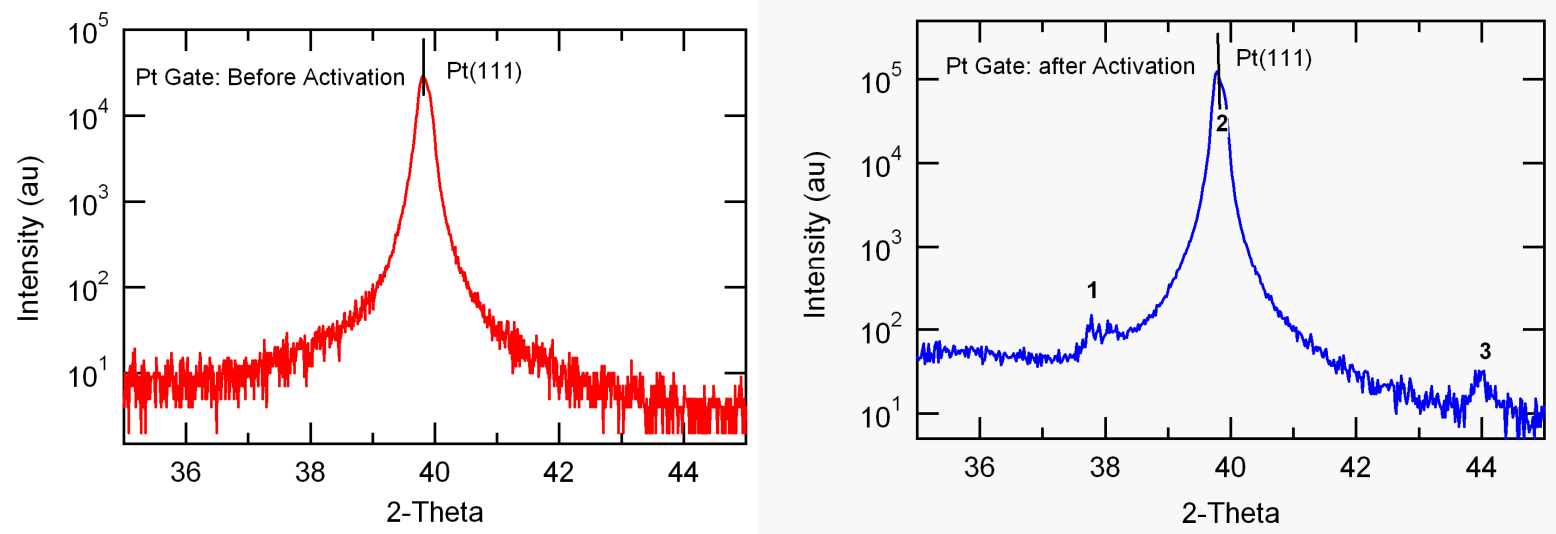

Fig. 4.1.3. X-ray diffraction scans of Pt sensing layers deposited on oxidized SiC. (a) Pt gate before activation, and (b) after activation. The data shows that the Pt layers are highly textured (111) films. 


\subsection{Effect of activation on sensor sensitivity}

In the previous report, we demonstrated (and repeat here) the effect of gate activation on sensing measurements of the $\mathrm{SiC}$ sensors. The sensor measurements were made by monitoring the gate voltage, while holding the capacitance fixed at midgap bias. The device was initially exposed to laboratory air and then to $10 \% \mathrm{H}_{2}$ (balances $\mathrm{N}_{2}$ ). We tried two different activation processes. First, from $1000 \mathrm{~s}$ to $5000 \mathrm{~s}$ the sensor was exposed to alternating flows of (i) $10 \% \mathrm{H}_{2}$ plus $1 \% \mathrm{O}_{2}$ (balance $\mathrm{N}_{2}$ ) at $200 \mathrm{ml} / \mathrm{min}$ followed by (ii) $1 \% \mathrm{O}_{2}$ (balance $\mathrm{N}_{2}$ ) at $100 \mathrm{ml} / \mathrm{min}$ for $\sim 100 \mathrm{~s}$ each. Secondly, from $5000 \mathrm{~s}$ to $6500 \mathrm{~s}$ the sensor was exposed to alternating $100 \mathrm{ml} / \mathrm{min}$ flows of (i) $10 \% \mathrm{H}_{2}$ (balance $\mathrm{N}_{2}$ ) at 100 followed by (ii) $1 \% \mathrm{O}_{2}$ (balance $\mathrm{N}_{2}$ ) at 100 for about $100 \mathrm{~s}$ each.

As expected from theory the sensor signal shifts to a more negative potential in a reducing environment, due to the decrease in the metal/semiconductor barrier height in hydrogen. The device response to alternating reducing and oxidizing gases is initially small $(\sim 270 \mathrm{mV})$ and the baseline drifts upwards. These results are consistent with those of our colleagues in Linkoping [Spetz 2001]. After about 92 minutes of activation, the sensor signal stabilizes and the response to alternating between a purely reducing and oxidizing environment is $\sim 420 \mathrm{mV}$. As we have observed previously, the response to a gas exchange from oxygen to hydrogen is fast (reaching $93 \%$ of the steady state value in $\sim 3 \mathrm{~s})$ the response to changing from hydrogen to oxygen has both a fast $(\sim 5 \mathrm{~s})$ and slow component. Note that these measurements were taken using our slow Keithley data acquisition program, which has a several second response time, so the intrinsic sensor response may be significantly faster. 


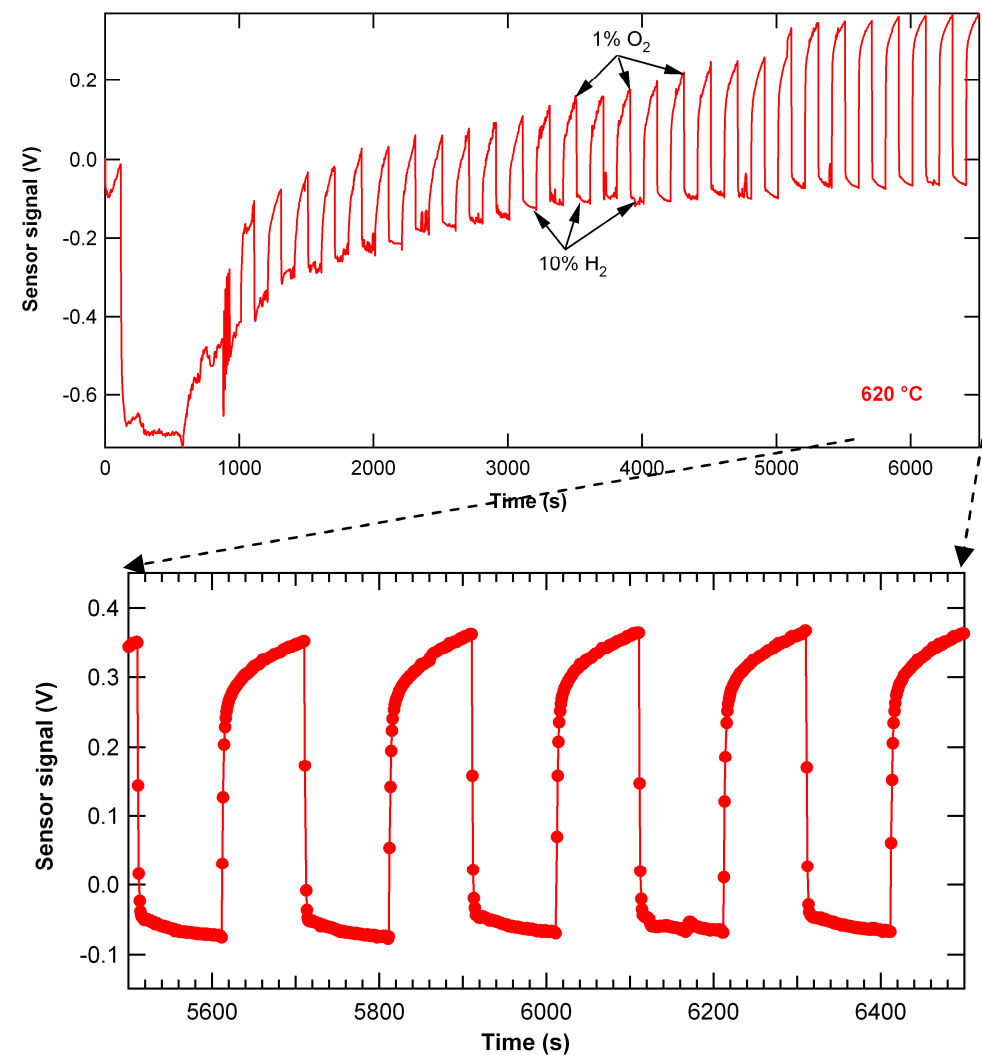

Fig. 4.2.1: Sensor signal during device activation at $620{ }^{\circ} \mathrm{C}$. The sensor is a $1 \mathrm{~mm}$ diameter $\mathrm{Pt}$ gate fabricated on a n-type $6 \mathrm{H}-\mathrm{SiC}$ substrate (bulk: $1.01 \times 10^{18} \mathrm{~N} / \mathrm{cm}^{3}$, epitaxial layer: $2 \times 10^{16} \mathrm{~N} / \mathrm{cm}^{3}$ ) with $39.2 \mathrm{~nm}$ thick $\mathrm{SiO}_{2}$ film grown via dry oxidation with an $\mathrm{NO}$ anneal. 


\subsection{Gate leakage measurements at high temperature}

Shown in Fig. 4.3.1 is the gate leakage current as a function of temperature for a $1 \mathrm{~mm}$ diameter metal- $\mathrm{SiO}_{2}-\mathrm{SiC}$ sensor. A large area device is attractive for sensing applications as the signal to noise ratio is proportional to the slope of the $\mathrm{C}-\mathrm{V}$ characteristic near mid-gap. A current density of $10 \mathrm{nA} / \mathrm{cm}^{2}$ was obtained at $630^{\circ} \mathrm{C}$.

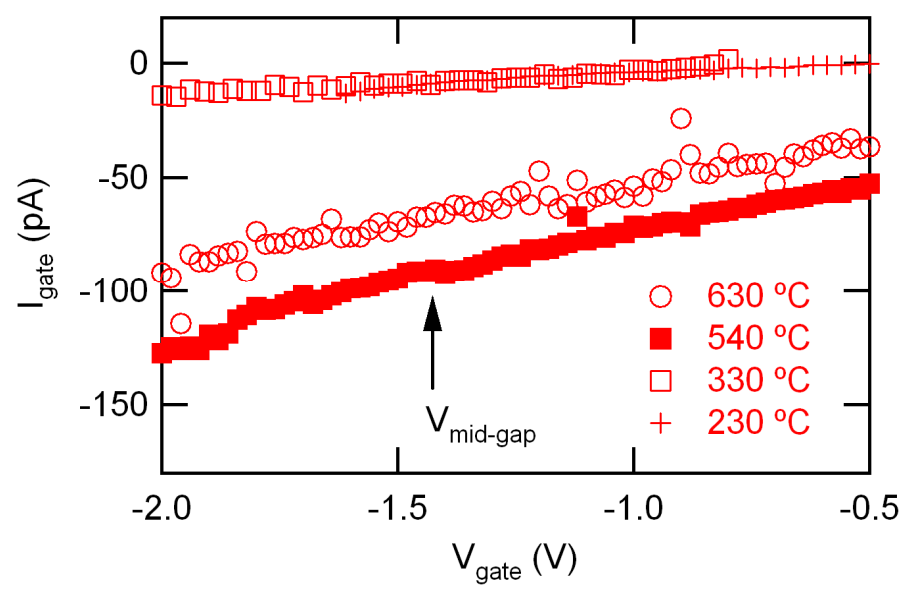

Fig. 4.3.1.: Gate leakage current as a function of voltage from $230-630^{\circ} \mathrm{C}$ for the device from Fig. 3.5.1.1. The differential resistance $\left(\mathrm{dI}_{\mathrm{g}} / \mathrm{V}_{\mathrm{g}}\right)^{-1}$ is constant in the voltage range around mid-gap bias, and as expected the magnitude decreases with increasing temperature. The current density is $10 \mathrm{nA} / \mathrm{cm}^{2}$ at 630 ${ }^{\circ} \mathrm{C}$ at mid-gap.

Oxide leakage measurements were made on three $6 \mathrm{H}-\mathrm{SiC}$ samples subjected to different thermal stress cycles. Shown in Fig. 4.3.2 are the results from sample1-3, after sequential heating at $330,430,540$ and $630{ }^{\circ} \mathrm{C}$. Sample 1 was measured only at $530{ }^{\circ} \mathrm{C}$ after 5 hours at high temperature; all the data points lie on top of each other. Continuous heating does not adversely affect the capacitors. The flat band voltage for all gates from both samples is close to theory.

As the primary mode of oxide breakdown at high temperatures is attributed to electron injection from the substrate, the gate leakage current was monitored as a function of temperature

- Sample 1 - irrespective of device location on chip (device 3-2, 4-1, 8-2) we observed the same current density

- In the $300-450{ }^{\circ} \mathrm{C}$ temperature range, all measured devices exhibit current density below $5 \mathrm{nA} / \mathrm{cm}^{2}$

- Above $450{ }^{\circ} \mathrm{C}$ there is a larger spread in the data, from $3-53 \mathrm{nA} / \mathrm{cm}^{2}$

- A few of larger gates $(\geq 500 \mu \mathrm{m})$ have leakage current densities $<10 \mathrm{nA} . \mathrm{cm}^{2}$ over the entire temperature range. 


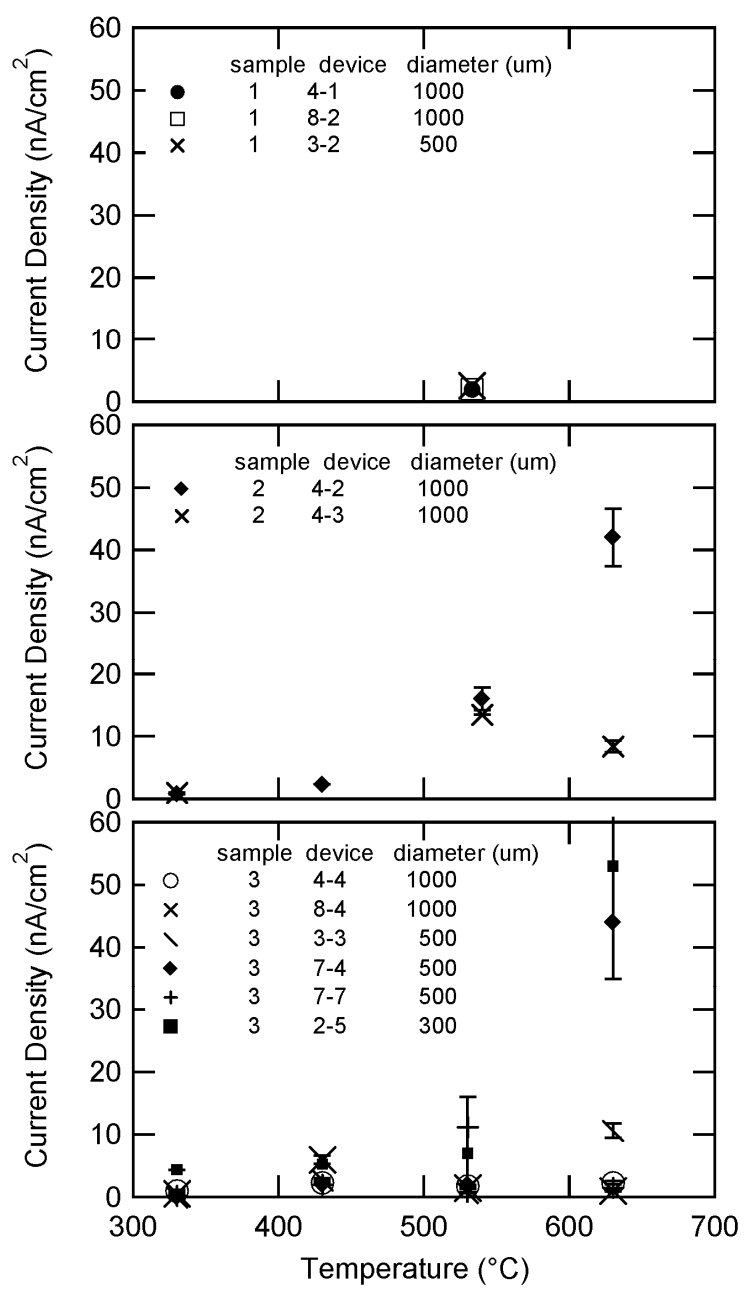

Fig.4.3.2. Temperature dependence of the gate leakage current density - Sample 1 - measured at $530^{\circ} \mathrm{C}$ after 5 hours of continuous heating

- Samples 2 \& 3 - measured at $330,430,530-540 \& 630^{\circ} \mathrm{C}$

- Device biased near mid-gap to optimize sensor performance.

Our results are very encouraging in terms of the long-term reliability of $\mathrm{SiC}$ fieldeffect sensors. It is especially promising that large area devices have such low leakage current densities up to $630^{\circ} \mathrm{C}$. The measurement techniques described here are relevant for reliability studies of $\mathrm{SiC}$ power devices, as they provide a platform for accelerated aging as well as time-dependent dielectric breakdown measurements at high temperature 


\subsection{Sensor response measurements in $\mathrm{UHV}$}

\subsubsection{Capacitance-Voltage curves}

Fig. 4.4.1.1 shows $1 \mathrm{MHz}$ capacitance-voltage curves measured in UHV for Gate \#43 of Sample $\mathrm{SiC} 7+\mathrm{I}+\mathrm{I}$, measured in both oxygen and hydrogen environments. For all measurements shown the voltage was scanned from accumulation to depletion at a rate of $0.2 \mathrm{~V} / \mathrm{s}$. The observed shift - approximately $100 \mathrm{mV}$ at mid-gap - is about $50 \times$ larger than the shifts observed on previous samples in UHV. We attribute this increase to the activation of the gates prior to installation in UHV.

The $\mathrm{C}-\mathrm{V}$ curve showed a gradual shift towards positive gate bias over the first few weeks of UHV experiments, as shown in the upper panel of Fig. 4.4.1.2. The C-V curve then stabilized, and was relatively insensitive to surface impurities, as shown in the lower panel. The $\mathrm{C}-\mathrm{V}$ characteristic also remained essentially stable through numerous temperature cycles, gas exposures, sulfur contamination and removal, and Auger spectroscopy measurements extending over many months.

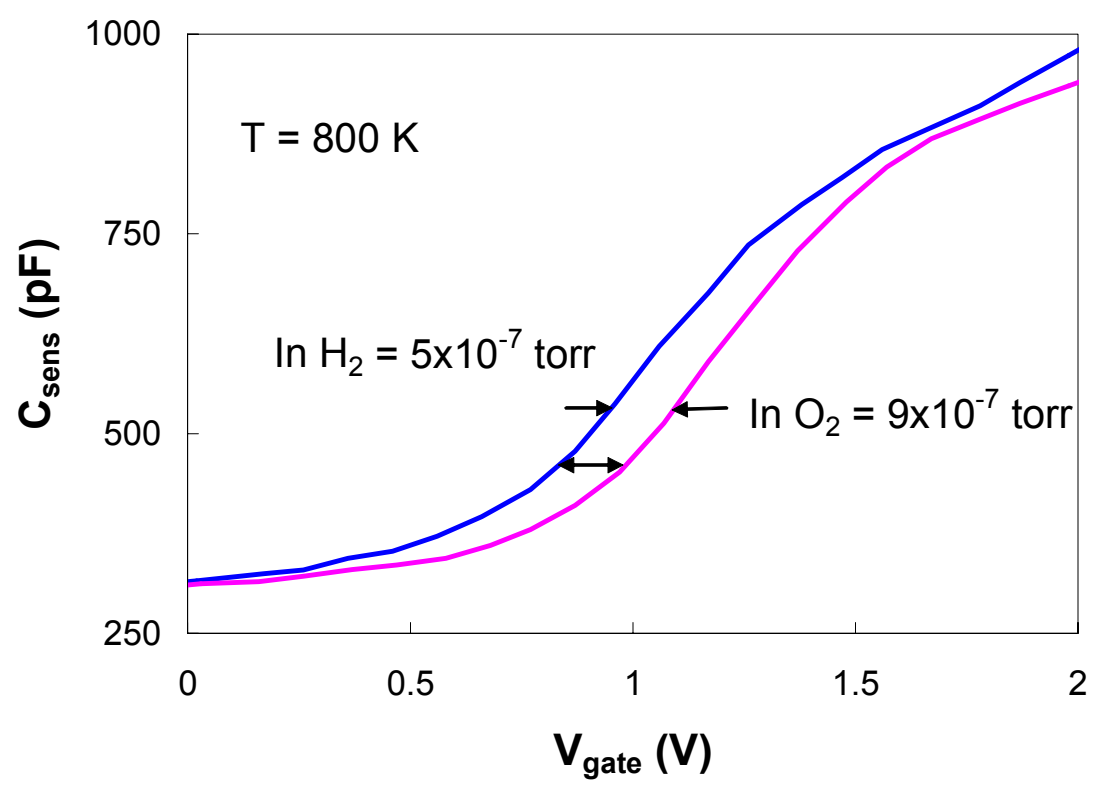

Fig. 4.4.1.1. $1 \mathrm{MHz} \mathrm{C}-\mathrm{V}$ characteristics in hydrogen and oxygen, measured in UHV. A $100 \mathrm{mV}$ shift at near midgap capacitance $(450 \mathrm{pF}$, marked by a double arrow) was observed. 

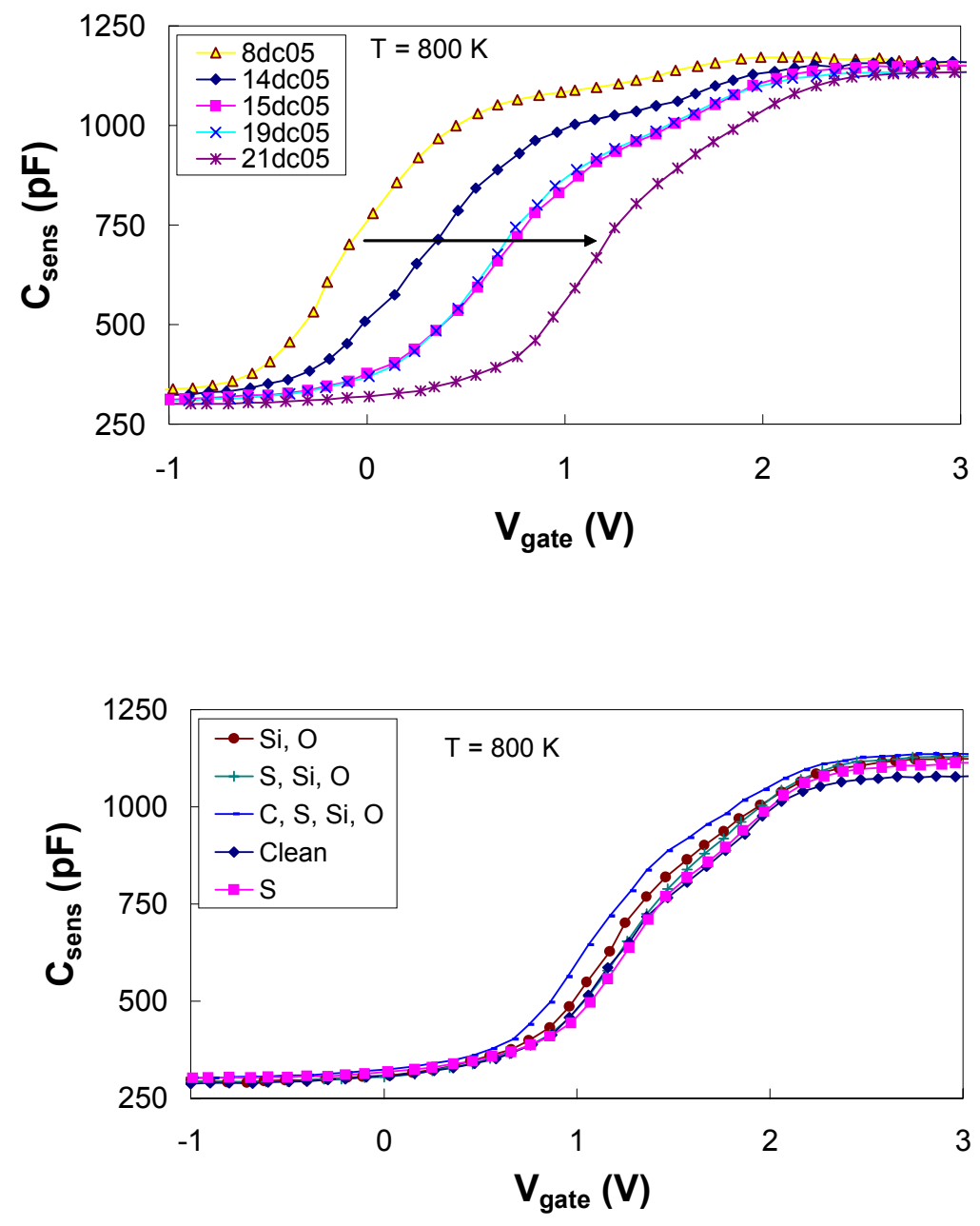

Fig. 4.4.1.2. Top: C-V characteristics over time, in UHV. As sensor measurements were carried out on the sample over a period of weeks, C-V curves shifted toward positive gate bias as the arrow on the plot indicates. The legend indicates the date/month/year of the $\mathrm{C}-\mathrm{V}$ measurement. Bottom: After midgap capacitance (450 $\mathrm{pF}$ ) reached $\sim 0.8 \mathrm{~V}$, the $\mathrm{C}-\mathrm{V}$ curve's shift stabilized, and was relatively insensitive to surface contamination (legend indicates contaminants observed in Auger spectra). All curves measured at $1 \mathrm{MHz}$, scanning from accumulation to depletion at $0.2 \mathrm{~V} / \mathrm{s}$. 


\subsubsection{Hydrogen sensitivity measurements}

The sensitivity of the device to hydrogen was characterized by measuring the gate voltage shift at constant capacitance while exposing the sample alternately to hydrogen and oxygen. Two typical sequences are shown in Fig. 4.4.2.1. The hydrogen pressure was varied over approximately two decades $\left(5 \times 10^{-8}\right.$ to $\left.5 \times 10^{-6} \mathrm{Torr}\right)$, with two pulses at each pressure. The resulting data were then plotted semilogarithmically to obtain a sensitivity value in $\mathrm{mV} / \mathrm{dec}$ de, as shown in Fig. 4.4.2.2. Over a number of measurements the sensitivity for clean samples fell consistently in the range of 20-30 $\mathrm{mV} /$ decade. This slope is about a factor of four greater than the $7 \mathrm{mV} /$ decade sensitivity observed in our earlier UHV measurements on a device with a gate that had not been fully activated. Fig. 4.4.2.3 compares the sensitivity measured on the present sample with the results reported in Phase I for a sample that was not fully activated. It is significantly lower, however, than the values observed in measurements at atmospheric pressure. The origin of this difference is not yet understood. It may be related to a difference in the kinetics of hydrogen site occupation and depletion under the very different pressure conditions of the two experiments. It is worth noting that the UHV experiments show a slow response to hydrogen (time constant $>500 \mathrm{~s}$ ) in addition to a fast response; no such effect has been seen with the sensor biased near mid-gap capacitance in measurements at atmospheric pressure.

Sensitivity measurements were also conducted after the deposition of sulfur on the gate surface (see section 4.5). It proved difficult to obtain reliable results, however, because of the rapid removal of sulfur when the sample was exposed to oxygen. This effect is illustrated in Fig. 4.4.2.4, in which Auger spectroscopy shows that a sulfurprecovered surface is thoroughly cleaned by the sequence of hydrogen and oxygen pulses used in measuring sensor response. The Auger probe beam has a spot size of about 0.1 $\mathrm{mm}$, much smaller than the gate size of $1 \mathrm{~mm}$, so it samples only the gate surface. The large peak near $150 \mathrm{eV}$ in the middle trace is due to sulfur; all of the other features in the traces are from Pt.

Nevertheless, a number of results strongly suggest that sulfur suppresses the size of the voltage shift, but may actually increase the slope of the voltage shift vs. hydrogen pressure graph. Fig. 4.4.2.5 compares two sensitivity measurements on the same sample before and after exposure to hydrogen sulfide (these data are not from the experiment shown in 4.4.2.1). Because of concerns about possible damage to the oxide, Auger spectroscopy was not used, so we do not have quantitative measures of surface composition or contamination. It is likely that for these measurements there were contaminants other than sulfur on the surface, since the oxygen pulses used in the sensitivity measurement apparently did not remove the sulfur, as occurs when the surface is initially clean. Still it is notable that the size of the voltage shift at the pressures used dropped dramatically after $\mathrm{H}_{2} \mathrm{~S}$ exposure, while the slope increased somewhat, from 30 to $38 \mathrm{mV} /$ decade.

Figure 4.4.2.6 illustrates both the reduction of hydrogen sensitivity by sulfur deposition and the difficulty of accurately measuring that reduction. The left side shows a sequence of hydrogen and oxygen pulses on a device with a clean Pt gate, with the bias shift shown by the lowest trace. The right side shows a similar set of measurements after the sample was exposed to hydrogen sulfide. The first two hydrogen/oxygen cycles after 
the $\mathrm{H}_{2} \mathrm{~S}$ dose give reduced voltage shifts, but then the signal levels return to their cleansurface values as the sulfur is removed by the oxygen exposure (see section 4.5.3 below).

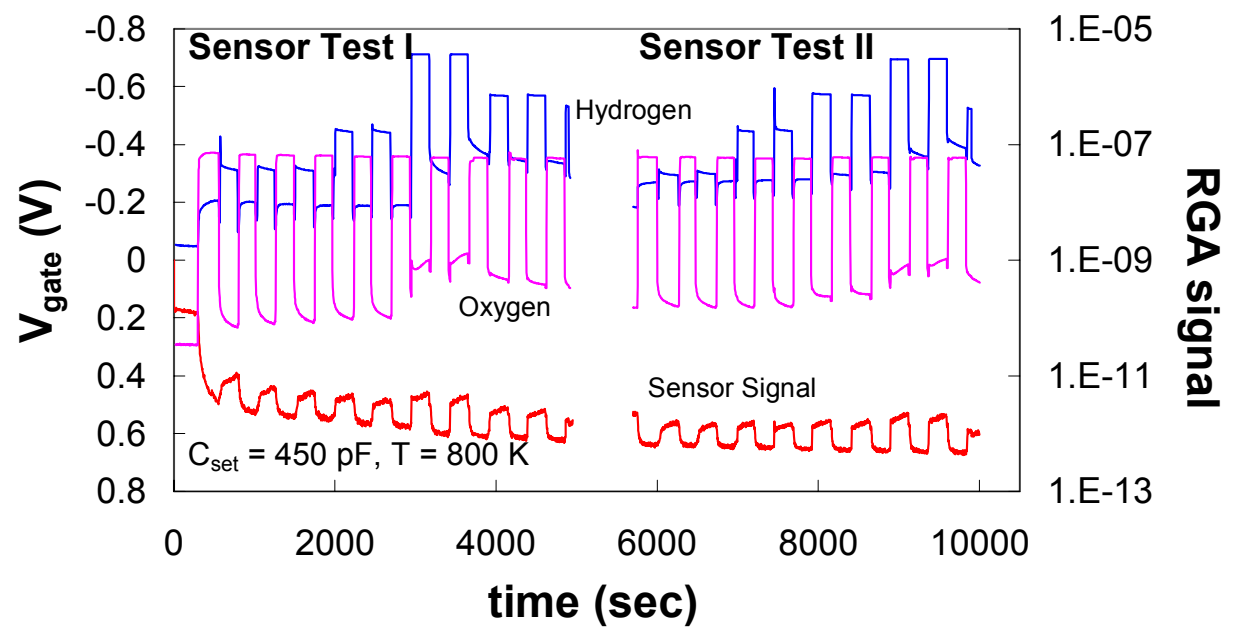

Fig. 4.4.2.1. Sensor signal and gas pressures monitored during sensing tests on a clean sample surface. Gas pressures not corrected for doser enhancement or RGA sensitivity. Note the inverted scale for $\mathrm{V}_{\text {gate }}$; in hydrogen the gate bias shifts to lower values.

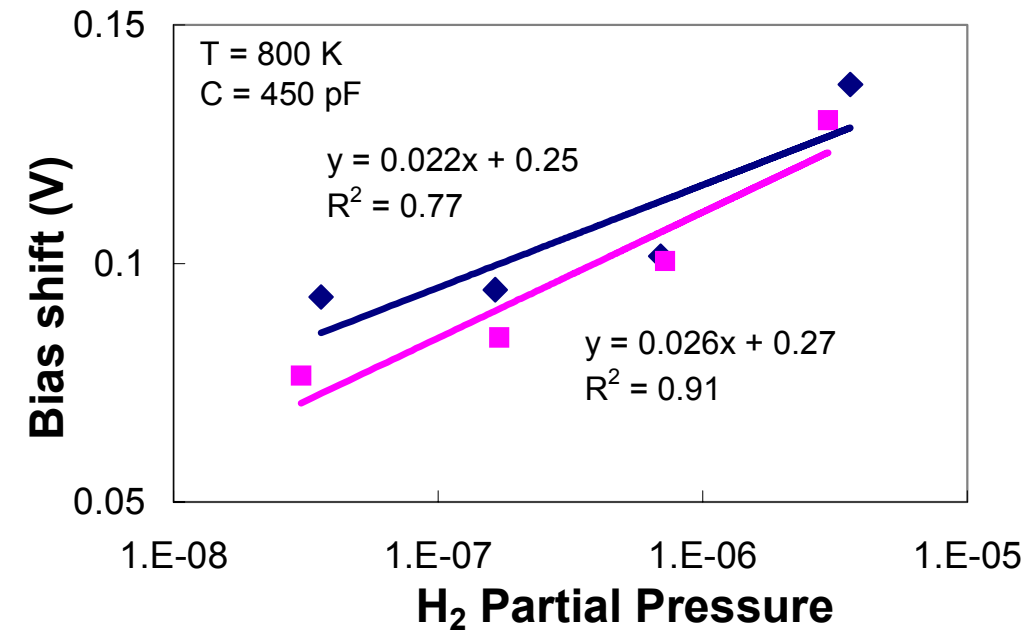

Fig. 4.4.2.2. Two separate measurements of hydrogen sensitivity, showing the level of reproducibility. 


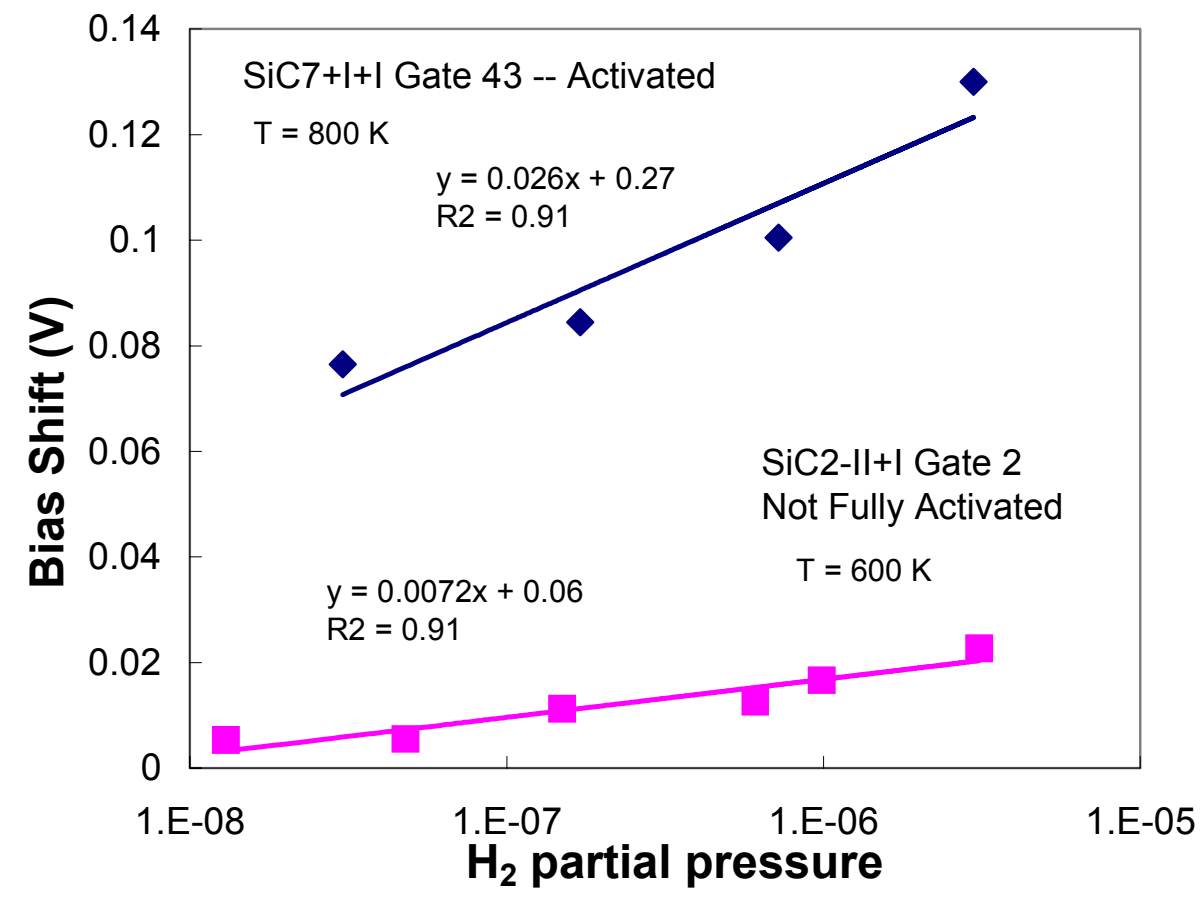

Fig. 4.4.2.3 Comparison of hydrogen response between activated (SiC2-II+I) and nonactivated $(\mathrm{SiC} 7+\mathrm{I}+\mathrm{I})$ samples, in $\mathrm{UHV}$. On the activated sample, the signal size was 10 times greater and the slope was 4 times greater. 


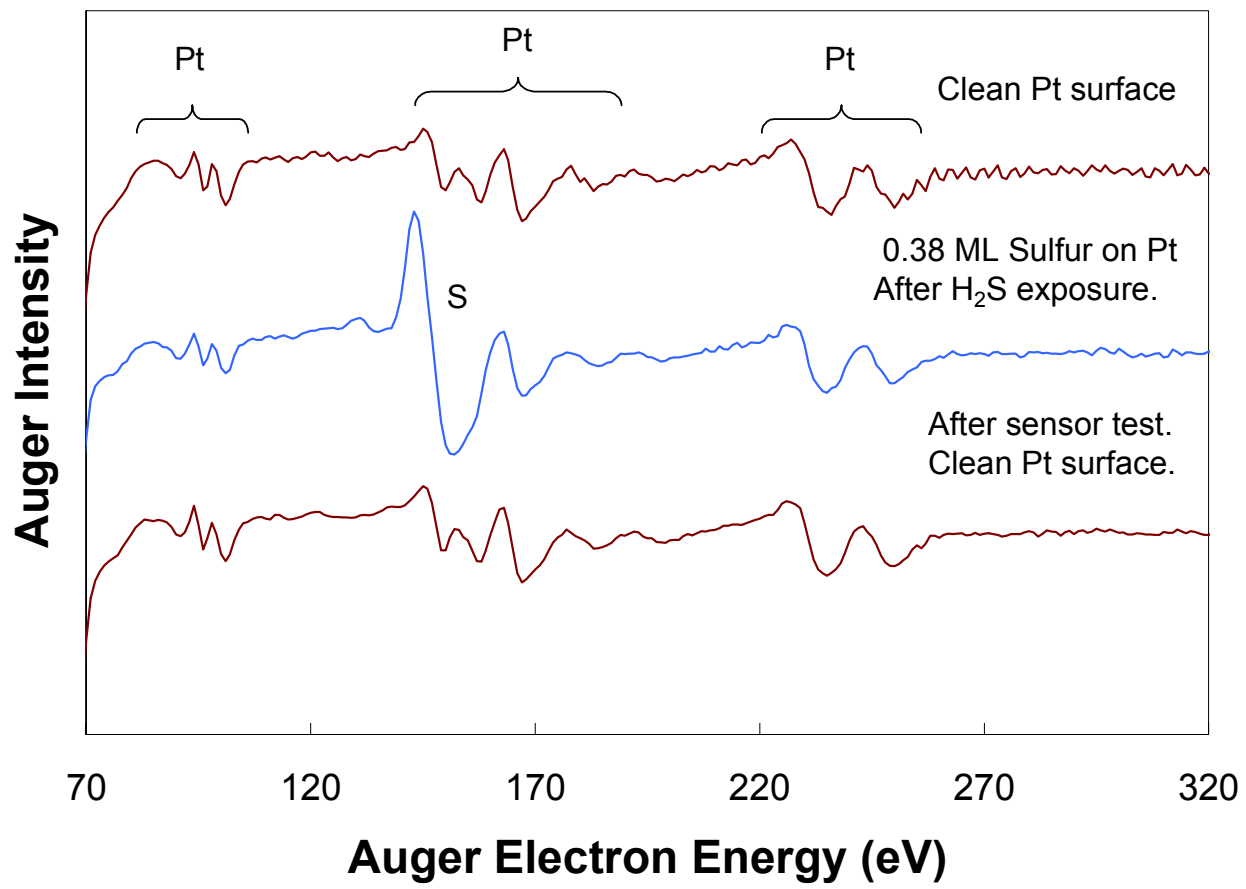

Fig. 4.4.2.4. Auger scans showing the cleaning effect of sensor measurements. The top trace shows a clean Pt surface. The sample was then exposed to hydrogen sulfide, producing a sulfur coverage of $0.38 \mathrm{ML}$, as shown in by the large S peak at $152 \mathrm{eV}$ in the middle trace. The bottom trace was measured after a series of sensor response measurements consisting of alternating hydrogen and oxygen pulses. The sulfur has been removed and the scan is indistinguishable from the original clean Pt trace. 


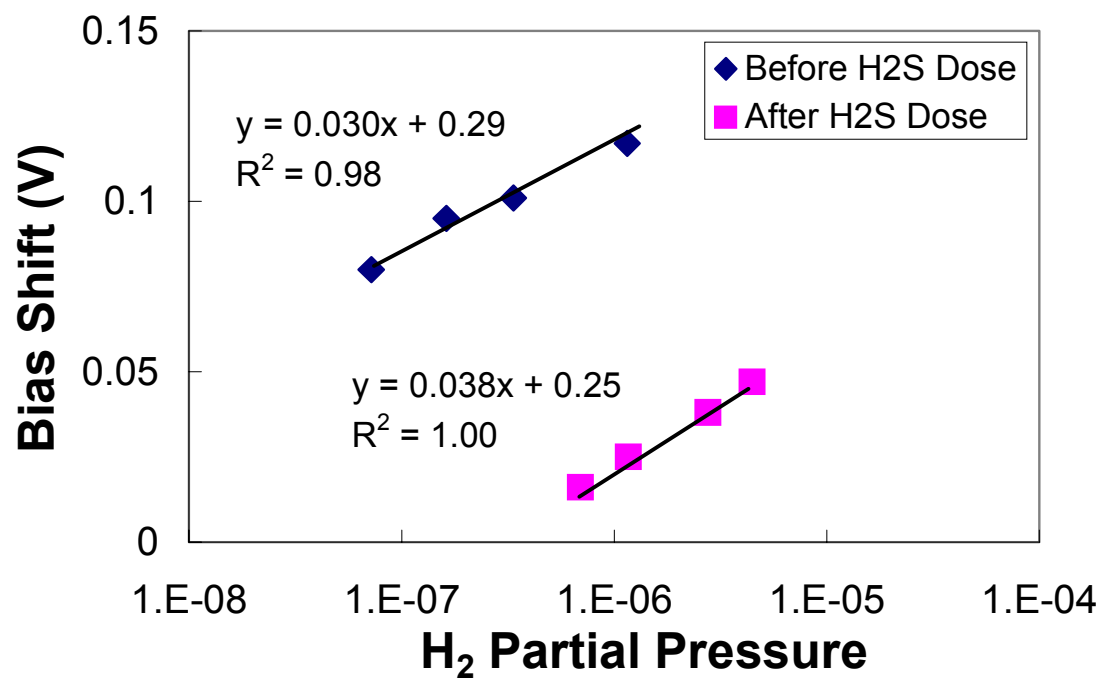

Fig. 4.4.2.5. Sensor responses in UHV to hydrogen partial pressure changes before and after $\mathrm{H}_{2} \mathrm{~S}$ dose. Surface conditions were not monitored with Auger spectroscopy. After hydrogen sulfide exposure, the signal size became $\sim 5$ times smaller, but the slope increased from 30 to $38 \mathrm{mV} /$ decade. 


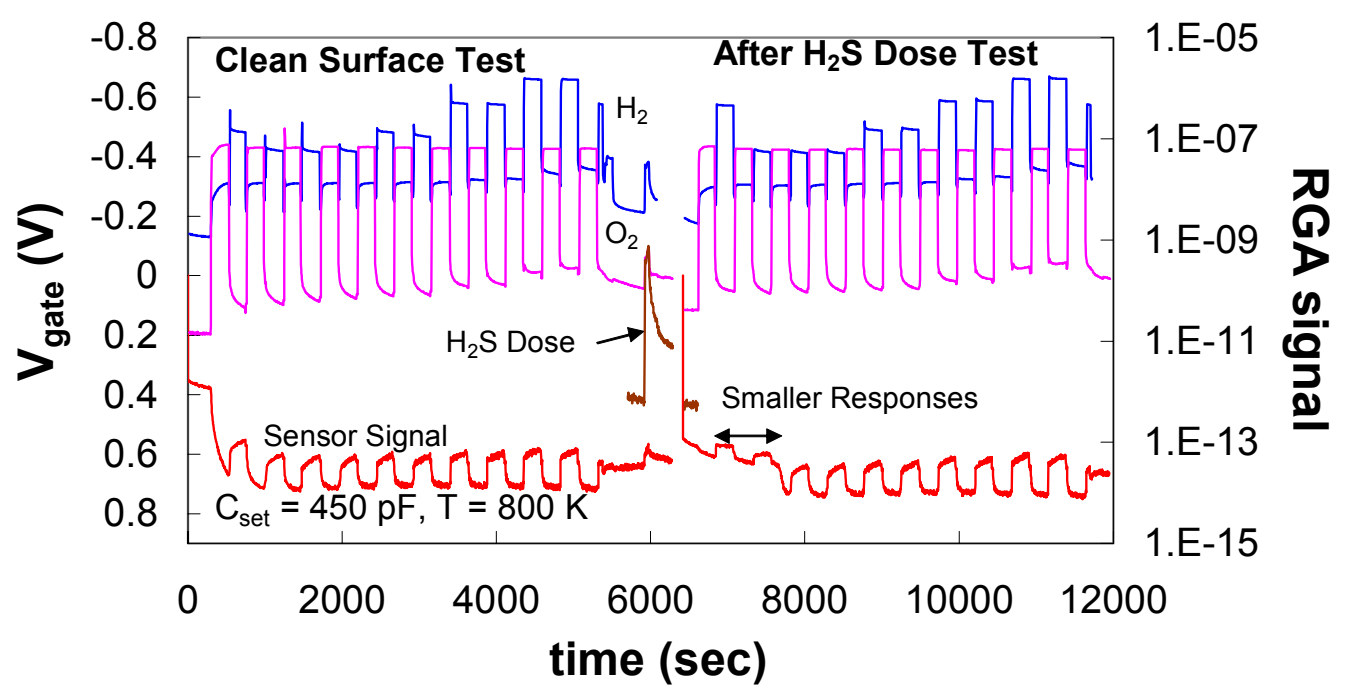

Fig. 4.4.2.6. Sensor signal and gas pressures monitored during sensing tests before and after hydrogen sulfide dose. Immediately after the hydrogen sulfide dose, the sensor response was smaller for two hydrogen/oxygen cycles (double arrow), but then returned to clean surface levels. The sequence of hydrogen pressures (in Torr), left to right, was: Clean surface $1.4 \times 10^{-7}, 6 \times 10^{-8}(3 \times), 1 \times 10^{-7}(2 \times), 5 \times 10^{-7}(2 \times), 1.5 \times$ $10^{-6}(2 \times)$; Sulfided surface $5 \times 10^{-7}, 5 \times 10^{-8}(3 \times), 1.5 \times 10^{-7}(2 \times), 5.5 \times 10^{-7}(2 \times), 1.5$ $\times 10^{6}(2 \times)$. All oxygen pulses were $6 \times 10^{-8}$ Torr. Gas pressures not corrected for doser enhancement or RGA sensitivity. Note the inverted scale for $V_{\text {gate }}$; in hydrogen the gate bias shifts to lower values. 


\subsection{UHV studies of sulfur surface chemistry on the Pt gate}

Sulfur compounds, particularly hydrogen sulfide $\left(\mathrm{H}_{2} \mathrm{~S}\right)$ are common impurities in the gas flow for many applications, and sulfur is a notorious poison for transition metal catalysts. It is therefore important to determine whether sulfur can build up on the Pt gate, whether such buildup is detrimental to sensor performance, whether it is reversible, and what gas conditions can either prevent the buildup or remove the sulfur after it is deposited. We have carried out a systematic investigation of sulfur surface chemistry on the gate of a working sensor, in ultrahigh vacuum. We are thereby able to use the tools of surface science - primarily Auger electron spectroscopy - to make quantitative measurements of sulfur concentration on the Pt surface at the sub-monolayer level.

The gas pressures accessible in these experiments are many orders of magnitude lower than would be encountered in applications. Our maximum usable pressure is about $10^{-6}$ Torr, or roughly $10^{-9}$ atmosphere. Because we have accurate control of the gases, however, we can control the ratios of relevant gases in ranges that are relevant to practical operating conditions.

\subsubsection{Sulfur deposition and coverage determination}

Sulfur was deposited on the gate by exposing the sample to a partial pressure of approximately $10^{-9}$ Torr $\mathrm{H}_{2} \mathrm{~S}$ for a period of about one minute, with the sample at a temperature of $800 \mathrm{~K}\left(530^{\circ} \mathrm{C}\right)$. Typically during this exposure the pressures of oxygen and hydrogen would be $1 \times 10^{-9}$ and $5 \times 10^{-8}$ Torr, respectively.

Sulfur surface coverage was determined using Auger spectroscopy, as illustrated in Fig. 4.5.1.1. Sulfur has a primary Auger peak at $152 \mathrm{eV}$, which overlaps a Pt Auger peak. The sulfur coverage is determined from the ratio of the peak-to-peak amplitude of the $152 \mathrm{eV}$ peak to that of the Pt peak at $237 \mathrm{eV}$. For the clean Pt surface this ratio is approximately 0.9 , and an increase of 2.95 has been shown to correspond to a sulfur coverage of $0.50 \mathrm{ML}$ (ML = monolayer; $1 \mathrm{ML}=1 \mathrm{~S}$ atom/surface $\mathrm{Pt}$ atom) [Bonzel 1973]. For other levels we assume a linear relationship between the Auger ratio and the sulfur surface coverage.

Fig. 4.5.1.2 shows the development of sulfur coverage during exposures to hydrogen sulfide in combination with various pressures of hydrogen and oxygen. In typical applications, the ratio of hydrogen to $\mathrm{H}_{2} \mathrm{~S}$ can be in the range of $10^{3}$ to $10^{5}\left(\mathrm{H}_{2}\right.$ concentration $\sim 25 \%, \mathrm{H}_{2} \mathrm{~S}$ concentration $\sim 25 \mathrm{ppm}$ ). In these experiments the pressures are much lower, but the $\mathrm{H}_{2} / \mathrm{H}_{2} \mathrm{~S}$ ratios are comparable. Experiments were also carried out with oxygen, $\left(\mathrm{O}_{2} / \mathrm{H}_{2} \mathrm{~S}\right.$ ratio $\left.\sim 10^{3}\right)$. Even with these very high ratios, sulfur accumulated readily on the surface. These results suggest that sulfur contamination could be a problem in sensing applications, despite the high levels of reducing or oxidizing gases relative to the sulfur concentration. It is therefore important to determine whether the sensor can be cleaned after contamination. 


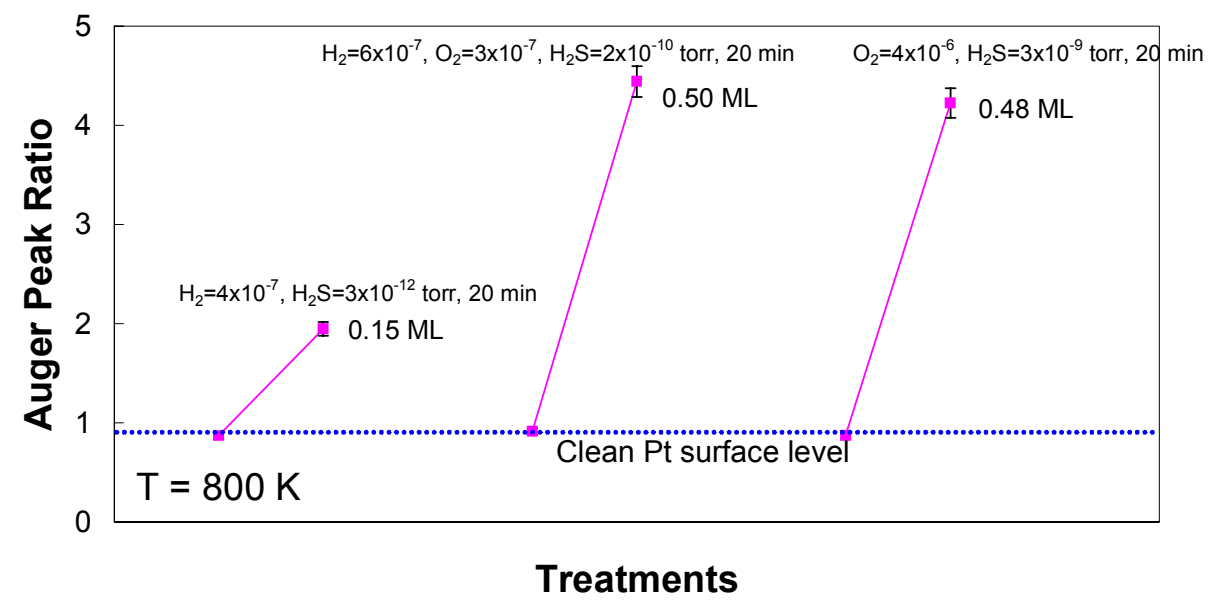

Fig. 4.5.1.2. Auger traces of sulfur coverage on the SiC7+I+I sample surface during sulfur contamination prevention tests. The sample surface temperature for all the tests on the plot was $800 \mathrm{~K}$. The conditions of each test, gas pulse sizes, compositions, and durations are indicated next to each data point. 


\subsubsection{Hydrogen cleaning tests}

Since hydrogen is a major constituent of the gas stream in likely sensor applications, and can in principle remove sulfur by forming hydrogen sulfide, it is of interest to determine whether exposure of a sulfur-contaminated surface to hydrogen can remove the sulfur.

Fig. 4.5.2.1 shows three tests in which a Pt gate was initially exposed to hydrogen sulfide to deposit a partial monolayer of sulfur. For each case the initial sulfur coverage is indicated. The sample was then heated to 800 or $900 \mathrm{~K}\left(530\right.$ or $\left.630^{\circ} \mathrm{C}\right)$ as indicated, and exposed to approximately $2 \times 10^{-7}$ Torr hydrogen gas for the indicated period. Although this is a very low pressure compared to atmosphere, it is large enough that every atomic site on the surface is exposed to a hydrogen molecule tens to hundreds of times during each treatment. Nevertheless no systematic decrease in sulfur coverage was observed. Evidently under these conditions hydrogen is ineffective at removing sulfur. It remains possible, of course, that sulfur removal by hydrogen could take place at the much higher gas levels encountered in practical applications.

Fig. 4.5.2.2 shows the hydrogen and oxygen pressure, and the sensor signal (gate voltage at constant capacitance) during successive hydrogen exposures at three different temperatures. At 700 and $800 \mathrm{~K}\left(430\right.$ and $\left.530^{\circ} \mathrm{C}\right)$ there is no observable response to hydrogen. At $900 \mathrm{~K}\left(630^{\circ} \mathrm{C}\right)$ there is a large and continuous voltage drift, but it is not correlated with the hydrogen signal. Such drifts have not been observed in measurements at atmospheric pressure, even at higher temperatures. The origin of the drift is currently unknown; one possibility is degradation of the silver paint contact in vacuum at this elevated temperature.

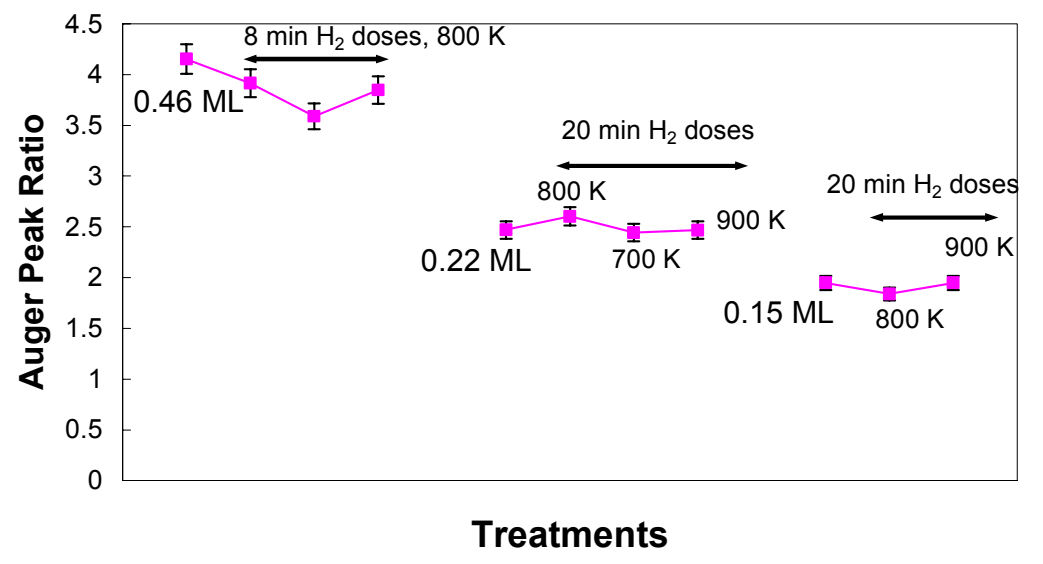

Fig. 4.5.2.1. Effects of hydrogen exposure on sulfur coverage. The hydrogen partial pressure in each case was about $2 \times 10^{-7}$ Torr, and the sample temperature and initial sulfur coverage are indicated. No significant decrease in sulfur level was observed. 


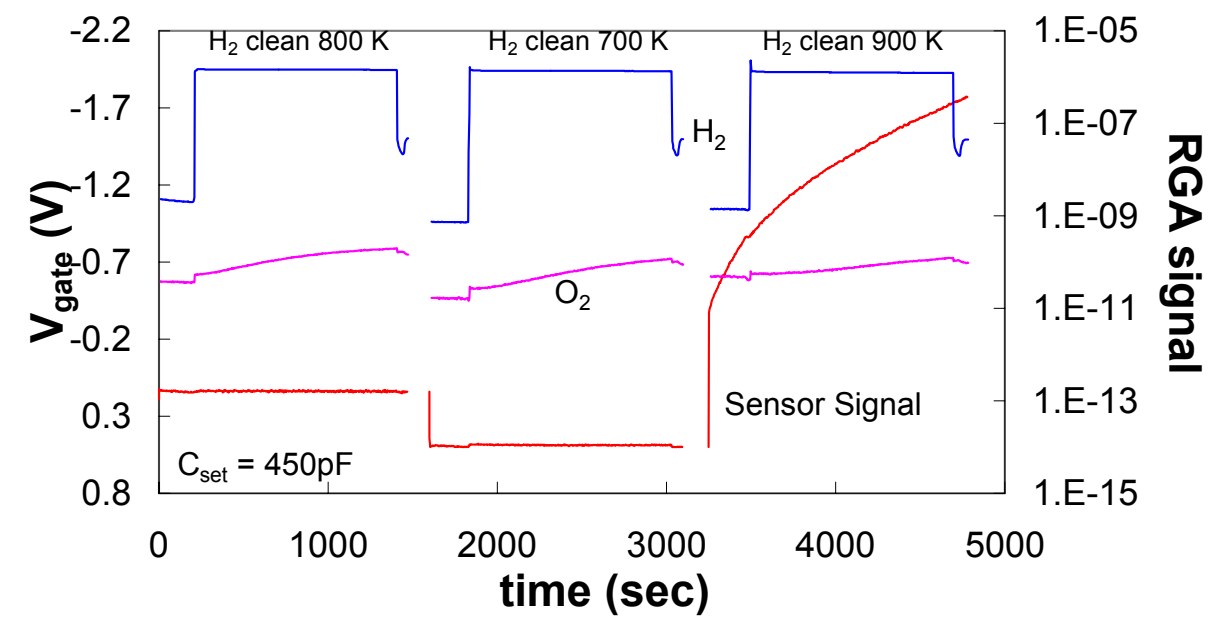

Fig. 4.5.2.2. Gas level and sensor signals monitored during hydrogen cleaning tests at three different sample temperatures. Note that the hydrogen signal on the plot is not corrected for RGA sensitivity (x0.4). 


\subsubsection{Oxygen cleaning tests}

It is also possible for oxygen to remove sulfur by reacting to form $\mathrm{SO}_{2}$. Accordingly we experimented with exposing sulfur-contaminated gates to oxygen. In this case sulfur was removed very rapidly unless the sulfur coverage was very high (at least $0.5 \mathrm{ML}$ ), and even in that case oxygen was able to remove the sulfur.

Fig. 4.5.3.1 shows a series of experiments at various initial sulfur coverages, for a sample temperature of $800 \mathrm{~K}\left(530^{\circ} \mathrm{C}\right)$. For sulfur coverages below about $0.33 \mathrm{ML}$, sulfur is removed completely within a few minutes at an oxygen pressure of $7 \times 10^{-7}$ Torr. At higher sulfur coverages the cleaning is slower, consistent with previous surface science experiments that found that open surface sites for the dissociation of $\mathrm{O}_{2}$ are necessary for the reaction between preadsorbed $\mathrm{S}$ and gas phase oxygen to occur on $\mathrm{Pt}(111)$ [Astegger 1982]. On the rough, grainy surface of the activated gate, however, there are apparently enough available sites for the reaction to occur, albeit at a reduced rate, even at sulfur coverages as high as $0.5 \mathrm{ML}$.

The figure also includes experiments in which hydrogen was admitted together with the oxygen, to see whether the hydrogen interferes with sulfur removal, as the water formation reaction competes for the available oxygen with sulfur oxidation. Even when an excess of hydrogen is present, the sulfur removal reaction proceeds largely unimpeded.

Fig. 4.5.3.2 shows the sensor response (gate voltage at constant capacitance) during three of the oxygen exposures for $0.5 \mathrm{ML}$ sulfur. Initially no change in gate voltage is observed, but a shift is visible when the sulfur is substantially removed from the surface. The $\mathrm{C}-\mathrm{V}$ curve after sulfur removal is typically shifted by $0.1-0.2 \mathrm{~V}$ relative to the curve before exposure to $\mathrm{H}_{2} \mathrm{~S}$; this is within the range of shifts typically seen from day to day even without sulfur exposure. There is no evidence that sulfur produces any irreversible changes.

More important is the response to hydrogen. Fig. 4.5.3.3 shows two sensitivity measurements, one before $\mathrm{H}_{2} \mathrm{~S}$ exposure and the other after $\mathrm{H}_{2} \mathrm{~S}$ exposure followed by cleaning in oxygen. The two curves are identical within experimental error.

These experiments indicate that even a device that has been severely contaminated with sulfur can be cleaned and fully regenerated simply by heating in an oxygen atmosphere, and that the presence of reducing gases, even in substantial quantities, does not interfere significantly with sulfur removal. 


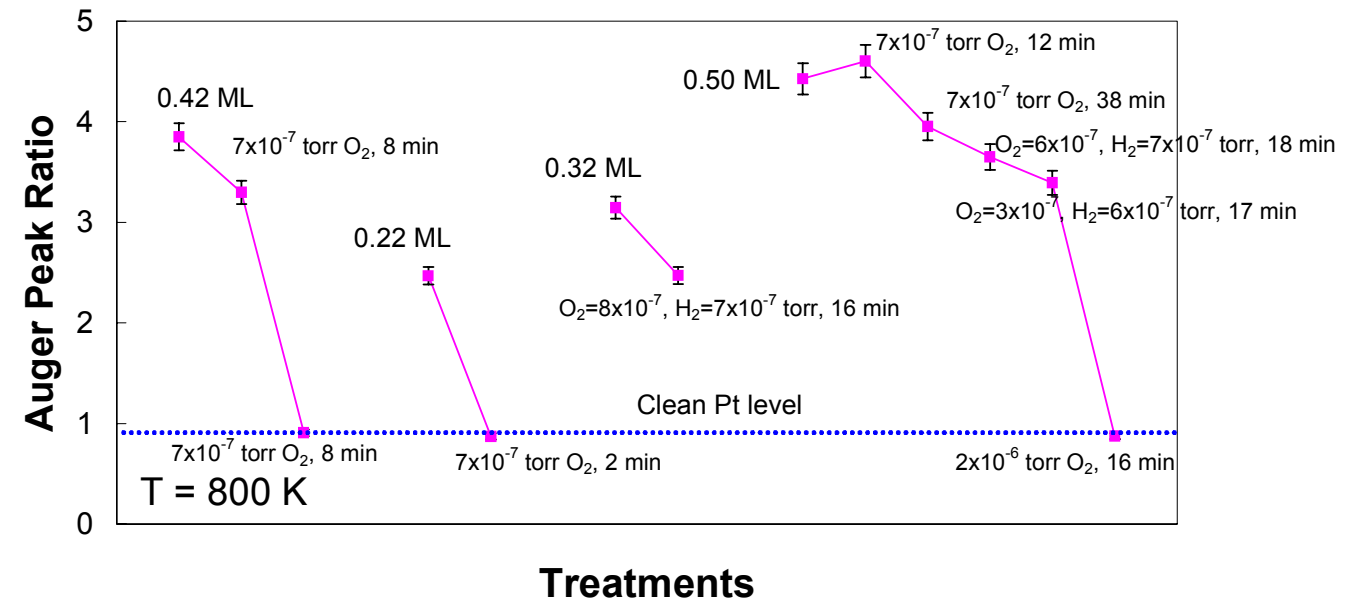

Fig. 4.5.3.1. Effects of oxygen exposure on sulfur coverage. The initial sulfur coverages, oxygen partial pressures, and exposure durations are indicated. The sample temperature was $800 \mathrm{~K}\left(530^{\circ} \mathrm{C}\right)$ in all cases. In some cases hydrogen was also present, but did not interfere significantly with sulfur removal. 


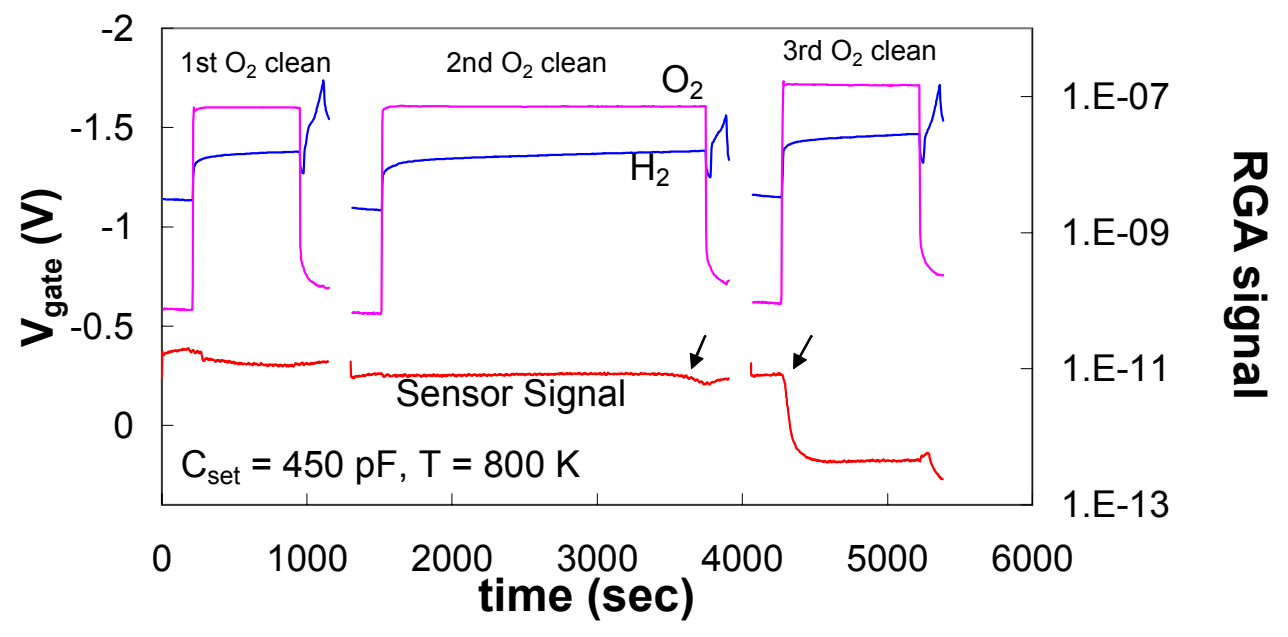

Fig. 4.5.3.2. Gas level and sensor signals monitored during oxygen cleaning (These represent the first, second and last cleaning cycles for $0.5 \mathrm{ML}$ initial sulfur coverage in Fig. 4.5.3.1). Note the reappearance of a sensor response as the sulfur is removed from the surface (arrows). Gas pressures not corrected for doser enhancement or RGA sensitivity. (17ap06Vt)

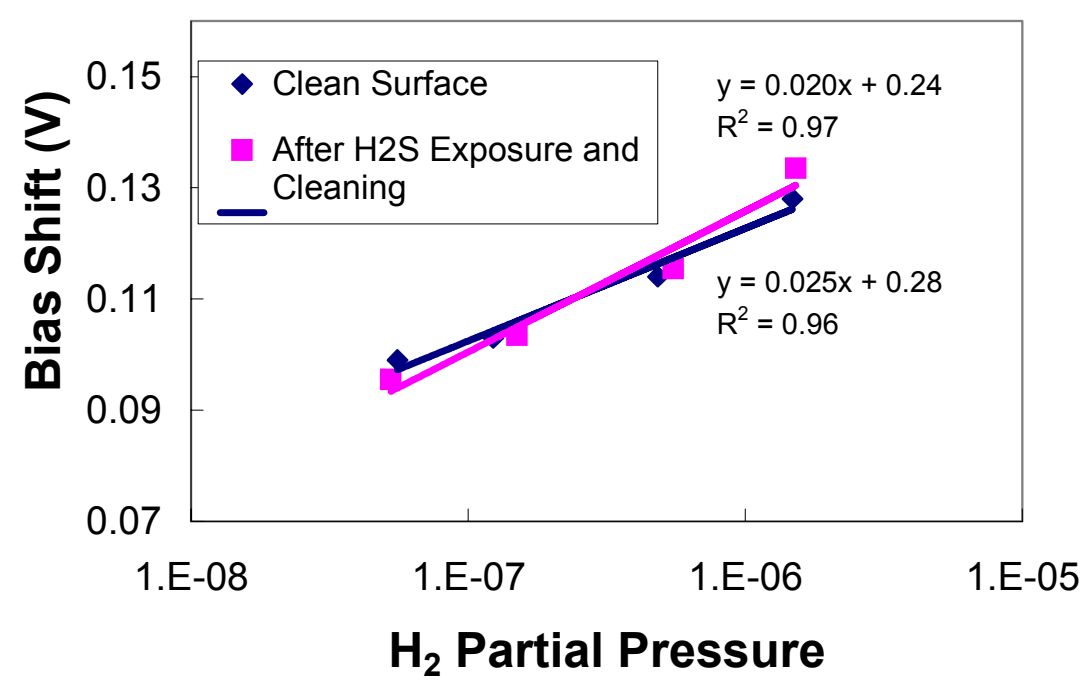

Fig. 4.5.3.3. Sensor responses to hydrogen partial pressure changes for a clean sample surface for the same sample after $\mathrm{H}_{2} \mathrm{~S}$ dosing and cleaning with oxygen. The curves are identical within experimental error. 


\subsubsection{Typical stream compositions and conditions for one or more potential applications for SiC based hydrogen gas sensors.}

Based on the information that is summarized in the Table 2.1.1 and the result of our study, SiC based hydrogen gas sensors have the capability of being used in a syngas application and for the 'cold gas cleaning processes' in an Integrated Gasification Combined Cycle (IGCC) Gasifier.

(1) Temperature requirements of potential applications:

Cold Gas Cleaning: $50-100{ }^{\circ} \mathrm{C}$ (MSU-SiC gas sensor: range of operation: up to $650{ }^{\circ} \mathrm{C}$ ) Hot Gas Cleaning: $500-600{ }^{\circ} \mathrm{C}$ (MSU-SiC gas sensor: range of operation: up to $650^{\circ} \mathrm{C}$ )

(2) Stream compositions in fuel cell and power plant application:

Based on the measurements made at the B3 micro-reactor facility at the NETL lab in Morgantown, WV (see sections 4.7.2, 4.7.3 and 4.7.4 of our previous report) the range of detection for the MSU SiC gas sensor at $620{ }^{\circ} \mathrm{C}$ for $\mathrm{H}_{2}$ is $52 \mathrm{ppm}-50 \%$. In addition the following levels of common "contaminants" did not adversely affect our hydrogen measurements:

$$
\begin{aligned}
& \mathrm{CH}_{4}: 5 \% \\
& \mathrm{CO}: 40 \% \\
& \mathrm{CO}_{2}: 40 \% \\
& \mathrm{H}_{2} \mathrm{~S}: 220 \mathrm{ppm}
\end{aligned}
$$

These values are all within the range of values of our two potential applications (see Table 2.1.1).

3) Stream gas flow rate and pressure:

The MSU-SiC gas sensor has been successfully used in a gas flow up to $1000 \mathrm{sccm}$. The high pressure performance of the sensor needs to be determined.

Syngas production from coal, which is then cleaned and used as fuel gas in a combined cycle power turbine, takes place in an integrated gasification combined cycle (IGCC) power plant. For optimal operation, however, use of syngas in advanced power production will require online monitoring of the syngas composition. SiC based gas sensing measurement systems (gas sensors) are good candidates for reliable measurements in the harsh and chemically corrosive operating conditions found within the coal gasifier. Other potential applications for $\mathrm{SiC}$ n-MOS gas sensor include monitoring the syngas fuel gas flow to a turbine or high temperature fuel cell. Table 4.6.1.1 lists the typical stream composition from: (i) the Cold-Gas Clean-up Zone for an IGCC gasifier, (ii) six different of fuel cells and (iii) a natural gas exhaust stream from several different power plants. 
Table 4.6.1.1

\begin{tabular}{|c|c|c|c|}
\hline Composition & $\begin{array}{c}\text { Fuel gas composition for Destec } \\
\text { Gasifier IGGC; Cold gas } \\
\text { cleaning }\end{array}$ & $\begin{array}{c}\text { Coal Gas composition } \\
\text { sources from Fuel cell CD }\end{array}$ & $\begin{array}{c}\text { Natural gas Fuel } \\
\text { Pressurized PAFC } \\
\text { (Anode Exhaust) }\end{array}$ \\
\hline $\mathrm{CH}_{4}$ & 800 ppm-0.1\% & $0.1-4.6 \%$ & $9 \%$ \\
\hline $\mathrm{H}_{2}$ & $24-39 \%$ & $16.1-33.9 \%$ & $29 \%$ \\
\hline $\mathrm{CO}_{2}$ & $5-9 \%$ & $1.5-15.5 \%$ & $51 \%$ \\
\hline $\mathrm{CO}$ & $31-50 \%$ & $5.8-63.1 \%$ & $2 \%$ \\
\hline $\mathrm{O}_{2}$ & $0-0.2 \%$ & - & - \\
\hline $\mathrm{H}_{2} \mathrm{~S}$ & $47-75 \mathrm{ppm}$ & $0.2-1.3 \%$ & - \\
\hline
\end{tabular}




\section{CONCLUSION}

We report on the reliability of $\mathrm{n}-\mathrm{MOS} \mathrm{SiC}$ capacitors, following thermal stress cycling in the 330 to $630{ }^{\circ} \mathrm{C}$ range. As the primary mode of oxide breakdown under these conditions is believed to be due to electron injection from the substrate, we have measured the gate leakage current as a function of temperature. The gate dielectric was grown using dry oxidation with an $\mathrm{NO}$ anneal. For large area, $1 \mathrm{~mm}$ diameter, $6 \mathrm{H}-\mathrm{SiC}$ capacitors we obtain current densities as low as $10 \mathrm{nA} / \mathrm{cm}^{2}$ at $630{ }^{\circ} \mathrm{C}$. Statistical data on flat band voltages and gate leakage measurements from the array of 200 to $1000 \mu \mathrm{m}$ devices on $6 \mathrm{H}-\mathrm{SiC}$ substrates was presented. These results are very encouraging in terms of the long-term reliability of $\mathrm{SiC}$ field-effect sensors. Our measurement techniques are also relevant for reliability studies of $\mathrm{SiC}$ power devices, as they provide a platform for accelerated aging as well as time-dependent dielectric breakdown measurements at high temperature.

We have designed, constructed and brought into operation a "nano-reactor" assembly to simulate the gas temperature and flow rates encountered in the NETL microreactor. This system is compatible with the module developed in phase I for sensor testing under industrial conditions.

We have characterized the change in the gate surface morphology due to gate activation. In the characterization process, we collect both Bright-field (BF) and Darkfield (DF) images of a few gates, before and after the activation process. The results of this study revealed that the changes in surface morphology from a smooth and shiny surface to a rough-cloudy surface are a common characteristic of activated Pt gates. The structural study of the Pt gates before and after activation using x-ray diffraction (XRD) patterns showed the appearance of two smaller peaks which are probably attributable to bold for the wire-bonding. The structure of bottom part of Pt gate did not change and remind as a highly textured (111) fcc phase.

Through the use of a fully activated device and improved experimental procedures, we have obtained reproducible sensor response and surface chemistry measurements on working devices in UHV. We have focused on the effects of sulfur, because of its potential significance in practical applications. The results suggest that sulfur contamination of the gate surface may be a significant problem, as sulfur accumulates readily, even at the very high hydrogen/hydrogen sulfide ratios $\left(10^{3}-10^{5}\right)$ expected in applications. There are indications that the sulfur adversely affects sensor response. Hydrogen was not effective in removing the sulfur deposits, at the low pressures available in our system, but it is possible that sulfur removal would occur at an appreciable rate at the much higher pressures encountered in applications.

Even at the very low pressures characteristic of UHV experiments, however, oxygen was extremely efficient at removing deposited sulfur, especially at sulfur coverages below $0.33 \mathrm{ML}$. The experiments suggest, therefore, that even a device severely contaminated with sulfur could be easily restored to function by exposure to oxygen. 


\section{ACKNOWLEDGEMENTS}

The SiC samples were oxidized by Prof. John Williams, Dept. of Physics, Auburn University. Mr. Nate Verhanovitz wrote the programming our measurement software. We also thank Mr. Tom Palazzolo, Mr. Tom Hudson and Mr. Jim Munns, (from the MSU machine shop) for technical advice in the design and fabrication of the components of the sensor measurement setup. 


\section{REFERENCES}

[Afanas'ev 1996] V. V. Afanas'ev, M. Bassler, G. Pensl, and M. J. Schulz, "Band offsets and electronic structure of $\mathrm{SiC} / \mathrm{SiO}_{2}$ interfaces," J. Appl. Phys. 79, 3108 - 3114 (1996).

[Astegger 1982] St. Astegger and E. Bechtold, "Adsorption of sulfur dioxide and the interaction of coadsorbed oxygen and sulfur on Pt(111)," Surf. Sci. 122, 491 (1982).

[Beadle 1985] W. E. Beadle, J. C. Tsai and R. D. Plummer, Quick Reference Manual for Si Integrated Circuit Technology, 6-34, Wiley, New York (1985).

[Bonzel 1973] H.P. Bonzel and R. Ku, "Adsorbate interactions on a Pt(110) surface: 1. Sulfur and carbon monoxide," J. Chem. Phys. 58, 4617 (1973).

[Cree] Cree Research Inc., Durham, NC 27703, USA.

[Chung 2000] G. Y. Chung, C.C. Tin, J. R. Williams, K. McDonald, M. DiVentra, S. T.Pantelides, L. C. eldman and R. A. Weller, Appl. Phys. Lett, 76, 1713 (2000).

[Deal 1966] B. E. Deal, E. H. Snow and C. A. Mead, "Barrier energies in metal-silicon dioxide-silicon structures”, J. Phys. Chem. Solids 27, 1873 - 1879 (1966).

[Eriksson 1997] M. Eriksson, I. Lundstrom and 1.-G. Ekedahl, "A model of the Temkin isotherm behavior for hydrogen adsorption at $\mathrm{Pd}-\mathrm{SiO}_{2}$ interface," J. Appl. Phys. 82, 3143 (1997)

[Dannetun 1984] H.M. Dannetun, L.-G. Petersson, D. Söderberg and I. Lundström, “A hydrogen sensitive Pd-MOS structure working over a wide pressure range," Appl. Surf. Sci. 17, 259 (1984).

[Das 2004] M. K. Das "Recent advances in (0001) 4H-SiC MOS device technology", Mat. Sci. Forum 457 - 460, 1275 - 1280 (2004).

[Dimitrijev 2003] S. Dimitrijev and P. Jamet, "Advances in SiC power MOSFET technology”, Micro. Rel. 43, 225 -233 (2003).

[EMS] EMS On Line: http://cimesg1.epfl.ch/CIOLS/crystal4.pl

[Gerblinger(1991] J. Gerblinger and H. Meixner, "Fast oxygen sensor on sputtered strontium titanate", Sens.\&Act. B4 (1991) 99-102.

[Ghosh 2002] R. N. Ghosh, P. Tobias, S. Ejakov and B. Golding, "Interface States in High Temperature SiC Gas Sensing”, Proc. IEEE Sensors 2002, 2, 1120-1125, paper 6-4 (2002).

[Ghosh 2003] R. N. Ghosh, P. Tobias and B. Golding, "Influence of interface states on high temperature $\mathrm{SiC}$ sensors and electronics", in SiC - Material, Processing and Devices 2002, Mat. Res. Soc. Symp. Proc. 742, paper K7.5 (2003). invited

[Ghosh 2005A] R. N. Ghosh and P. Tobias, "SiC field-effect devices operating at high temperature", J. Elec. Mat. 34, Special issue on Nitrides, SiC and ZnO, 345 - 350 (2005). [Ghosh 2005B] R. N. Ghosh, H. Hu, M. Koochesfahani and P. Tobias, "Millisecond gas sensor characterization technique", to be submitted to Rev. Scientific. Instruments., July 2005.

[Ghosh 2006] R. N. Ghosh, R. Loloee, T. Isaacs-Smith and J. R. Williams, "High temperature reliability of SiC n-MOS devices up to $630^{\circ} \mathrm{C}^{\prime}$, Mat. Sci. Forum, Silicon Carbide and Related Materials 2005, paper 3291. 
[Goodman 1965] A. M. Goodman and J. J. O-Neill, "Photoemission of electrons from metals into silicon dioxide", J. Appl. Phys. 37, 3580 -3583 (1966).

[Gland 1983] J.L. Gland and E.B. Kollin, "Carbon monoxide oxidation on the $\operatorname{Pt}(111)$ surface: Temperature programmed reaction of coadsorbed atomic oxygen and carbon monoxide," J. Chem. Phys. 78, 963 (1983).

[Katsuta 1979] H. Katsuta ad R. B. McLellan, J. Phys. Chem. Solids, "Diffusivity, Permeability and Solubility of Hydrogen in Platinum”, 40, 697-699, (1979).

[Kelleter 1992] J. Kelleter, G. Schull, C.D. Kohl, U. Gruner, A. Kraft, H. Wollnik, "Novel method for studying the kinetics of surface-reactions at submolecular exposures decomposition of acetic acid on palladium foil", Surface and Interface Analysis 19, 1-12 (1992) 581-585.

[Krastev 1998] E.T. Krastev and R.G. Tobin, "Ultrahigh vacuum sample transfer system with multiple electrical connections and grazing optical access," J. Vac. Sci. Technol. A 16, 743 (1998).

[Kuhl 1995] D.E. Kuhl and R.G. Tobin, "On the design of capillary and effusive gas dosers for surface science,” Rev. Sci. Instrum. 66, 3016 (1995).

[Lipkin 1996] L. A. Lipkin and J. W. Palmour, "Improved Oxidation Procedures for Reduced $\mathrm{SiO}_{2} / \mathrm{SiC}$ Defects”, J. Electron. Mater., 25, 909-915, (1996).

[Lozano 1992] Lozano, Xip, and Hanson, Experiments in Fluids, 13, p. 369, (1992). [Lundstrom 1976] I. Lundström and T. DiStefano, "Influence of Hydrogen on $\mathrm{Pt}_{-\mathrm{SiO}}-\mathrm{Si}$ Structures", Sol. St. Comm. 19, 871-875 (1976).

[Maranowski 1998] M. M. Maranowski and J. A. Cooper, Jr., “Time-DependentDielectric-Breakdown Measurements of Thermal Oxides on N-Type 6H-SiC", IEEE Trans. Electron. Devices 46, 520-524 (1999).

[McBride 1991] J.R. McBride, G.W. Graham, C.R. Peters, and W.H. Weber, "Growth and characterization of reactively sputtered thin-film platinum oxides, J. Appl. Phys. 69, 1596 (1991).

[Nakagomi 2001] S. Nakagomi, Y. Shindo, and Y. Kokubun, "Stability of electrical properties of high-temperature operated H-2 sensor based on Pt-I-SiC diode" Phys. Stat.

Solidi A 185, 33-38 (2001).

[Petersson 1985] L.-G. Petersson, H.M. Dannetun, J. Fogelberg and I. Lundström, "Hydrogen adsorption states at the external and internal palladium surfaces of a palladium-silicon dioxide-silicon structure,” J. Appl. Phys. 58, 404 (1985).

[Piconics] Piconics Inc., Tyngsboro MA 01879.

[Pierret 1990] R.F. Pierret, Field Effect Devices, vol. 2 of Modular Series on Solid State Devices, G. W. Neudeck and R.F. Pierret, eds., $2^{\text {nd }}$ ed. (Addison-Wesley, Reading MA, 1990).

[Salomonsson 2003] A. Salomonsson, "Catalytic reactions and hydrogen sensing with Ptand Pd-MIS devices", Licentiate thesis, Linkoping Univversity (2003).

[Samman 2000] A. Samman, S. Gebremariam S, L. Rimai L, X. Zhang, J. Hangas and G. W. Auner, "Silicon-carbide MOS Capacitors with Laser-ablated Pt Gate as Combustible Gas Sensors”, Sensor. Actuat. B-Chem. 63, 91-102 (2000). 
[Senzaki 2005] J. Senzaki, M. Goto, K. Kojima, K. Yamabe and K. Fukuda, “A longterm reliability of thermal oxides grown on n-type 4H-SiC wafer", Mat. Sci. Forum 457 460, 1269 - 1274 (2004).

[Serina 2001] F. Serina, K. Y. S. Ng, C. Huang, G. W. Auner, L. Rimai and R. Naik, "Pd/AlN/SiC Thin-film Devices for Selective Hydrogen Sensing", Appl. Phys. Lett. 79, 3350-3352 (2001).

[Skelton 1999] D.C. Skelton, R.G. Tobin, D.K. Lambert, C.L. DiMaggio, and G.B. Fisher, Oxidation of CO on Gold-Covered Pt(335), J. Phys. Chem. B 103, 964-971 (1999).

[Spetz 2001] A. Lloyd Spetz, L. Unéus, H. Svennningstorp, P. Tobias, L. G. Ekedahl, O. Larsson, A. Göras, S. Savage, C. Harris, P. Mårtensson, R. Wigren, P. Salomonsson, B. Häggendahl, P. Ljung, M. Mattsson and I. Lundström, "SiC Based Field Effect Gas Sensors for Industrial Applications”, Phys. Stat. Solidi A 185, 15-25, (2001).

[Summers 1969] R.L. Summers, NASA Technical Note TND-5285, 1969.

[Szabo 1989] A. Szabó, M. Kiskinova and J.T. Yates, Jr., "Carbon monoxide-oxygen interaction on the $\operatorname{Pt}(111)$ surface: An electron stimulated desorption ion angular distribution (ESDIAD) study," J. Chem. Phys. 90, 4604 (1989).

[Sze 1981] S. M. Sze, Physics of semiconductor devices, Wiley, p. 395-397, ISBN 047105661-8 (1981).

[Tobias 2003A] P. Tobias, B. Golding and R. N. Ghosh, "Interface states in hightemperature gas sensors based on silicon carbide", invited issue of IEEE Sensors Jour. 2, 543-547, (2003).

[Tobias 2003B] P. Tobias, B. Golding and R. N. Ghosh, "Sensing mechanisms of high temperature silicon carbide field-effect devices" TRANSDUCERS 2003 (12th

International Conference Solid-State Sensors, Actuators and Microsystems) 1, 416 - 419, (2003).

[Wang] X. W. Wang, Z. J. Luo and T. P. Ma, "High-temperature characteristics of highquality $\mathrm{SiC}$ MIS capacitors with O/N/O gate dielectric", IEEE Trans. Electron Devices 47, 458 - 463 (2000).

[Williams 1965] R. Williams "Photoemission of electrons from Si into silicon dioxide", Phys. Rev. 140, A569 - A575 (1965). 
BIBLIOGRAPHY

None 


\section{LIST OF ACRONYMS AND ABBREVIATIONS}

$\mathrm{SiC}$ - silicon carbide

$\mathrm{SiO}_{2}-$ silicon dioxide

$\mathrm{MISiC}$ - metal insulator silicon carbide (device)

Quasi-static - calculated C-V from the charge flowing onto a sensor at each voltage step

TPD - temperature programmed desorption

QMS - quadrupole mass spectrometer

AES - Auger electron spectroscopy

UHV - ultra high vacuum

PID - proportional-integral-derivative 